\title{
Focus on Meiosis
}

\section{Not all germ cells are created equal: Aspects of sexual dimorphism in mammalian meiosis}

\author{
Meisha A Morelli and Paula E Cohen \\ Department of Biomedical Sciences, Cornell University, Ithaca, NY 14853, USA \\ Correspondence should be addressed to P E Cohen; Email: pc242@cornell.edu
}

\begin{abstract}
The study of mammalian meiosis is complicated by the timing of meiotic events in females and by the intermingling of meiotic sub-stages with somatic cells in the gonad of both sexes. In addition, studies of mouse mutants for different meiotic regulators have revealed significant differences in the stringency of meiotic events in males versus females. This sexual dimorphism implies that the processes of recombination and homologous chromosome pairing, while being controlled by similar genetic pathways, are subject to different levels of checkpoint control in males and females. This review is focused on the emerging picture of sexual dimorphism exhibited by mammalian germ cells using evidence from the broad range of meiotic mutants now available in the mouse. Many of these mouse mutants display distinct differences in meiotic progression and/or dysfunction in males versus females, and their continued study will allow us to understand the molecular basis for the sex-specific differences observed during prophase I progression.

Reproduction (2005) 130 761-781
\end{abstract}

\section{Introduction}

Meiosis is a specialized cell division process that is essential for the propagation of all sexually reproducing organisms. In meiosis, a diploid cell divides to generate haploid daughters. It differs from mitosis in that the germ cell divides twice after a single DNA replication event, firstly by separating homologous (paternal/maternal) chromosomes and then by separating sister chromatids. During meiosis I, homologous chromosomes are separated into two daughter cells. The cell then proceeds to meiosis II without an intervening DNA replication event. In meiosis II, sister chromatids are separated into daughter cells creating, in males at least, four haploid cells (or gametes). In females, half of the chromosomes from the first meiotic division (MI) are packaged into a separate cellular structure known as a polar body. A second polar body forms at the second meiotic division (MII) that serves as a receptacle for half the products of the second meiotic division. The result in female mammals is the formation of a single haploid nucleus within the oocyte and two polar bodies that lie alongside the oocyte at fertilization (note that the oocyte itself is never truly haploid since the sperm has already penetrated the ooplasm prior to the completion of MII).

Meiosis I is divided into four stages: prophase, metaphase, anaphase, and telophase. Prophase I features most of the defining events that differentiate meiosis from mitosis. This includes homolog pairing as well as double stranded break (DSB) formation and resolution leading to crossover/recombination between homologus chromosomes. Prophase I is further divided into five substages: leptonema (adjective; leptotene), zygonema (adjective; zygotene), pachynema (adjective; pachytene), diplonema (adjective; diplotene) and diakenesis. A proteinaceous, meiosis-specific structure called the Synaptonemal Complex (SC) is present during prophase I. It is composed of two lateral elements (LE; which in pachytene become known as axial elements, $\mathrm{AE}$ ), which form along the entire length of each sister chromatid, and one central element (CE) which 'zippers up' the two lateral elements and binds the two homologous chromosomes in a process called synapsis. The different stages of prophase I are defined by the formation of the SC and can be tracked by inmmunostaining of SC components, particularly the LE protein, synaptonemal complex protein 3 (SYCP3), and the CE protein, synaptonemal complex protein 1 (SYCP1), for examples, see Baarends \& Grootegoed (2003), Kolas \& Cohen (2004), Lenzi et al. (2004), Moens et al. (2002) and Fig. 1. Crossing over is defined here as the exchange of genetic information between chromosomes of different parental origin. It allows for increased genetic variability 


\section{LEPTONEMA}

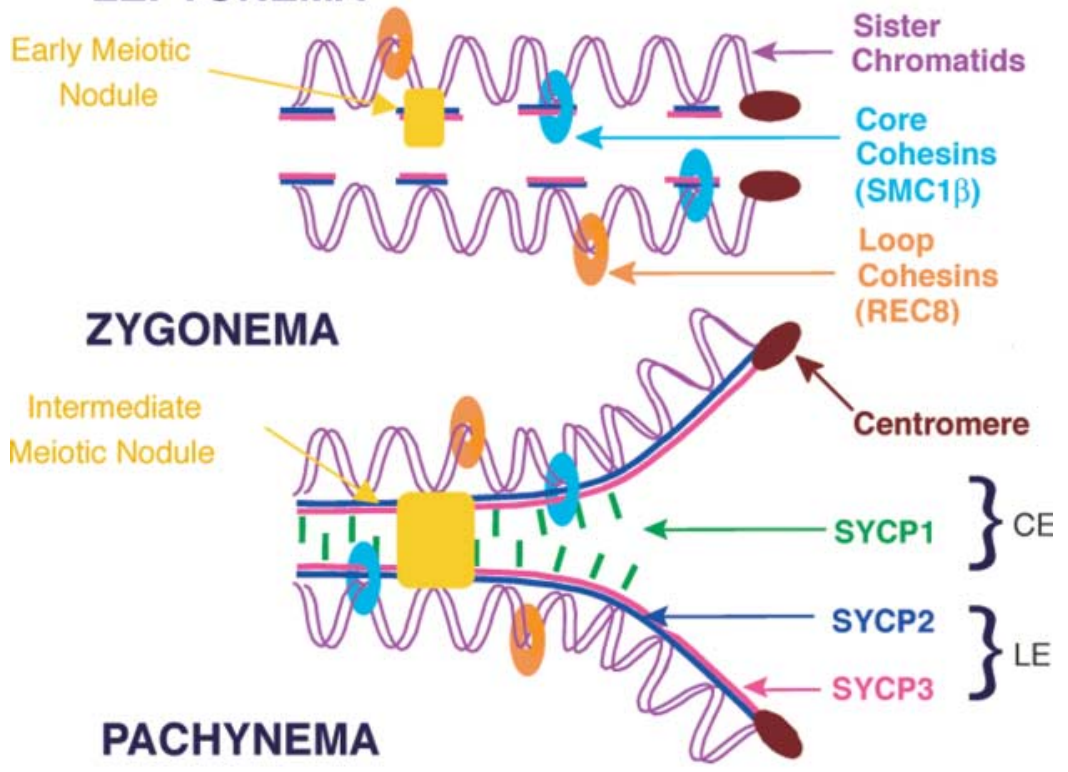

Figure 1 Synaptonemal Complex formation and chromosome behaviour during prophase I of mouse meiosis. This cartoon depicts the major protein components of the developing and mature synaptonemal complex and their relationship to the DNA. Meiotic nodules begin to accumulate in early leptonema and their constitutive components change as prophase I progresses, as indicated by the terms 'early', 'intermediate' and 'late'. Cohesin complexes are found in two varieties: core cohesin complexes include SMC1 $\beta$ and localize to the chromosome axes during prophase I (Jessberger 2002), while loop cohesins include REC8 and localize to the chromatin loops during prophase I (Jessberger 2002), CE; central element, LE; lateral element. in offspring as they are not restricted to inheriting either a paternal or maternal homolog for each chromosome, but can inherit a hybrid chromosome with genetic information from both parents. Thus crossing over is a pivotal step in meiosis and the primary purpose of the specialized events of meiotic prophase I.

The term sexual dimorphism has been used to describe morphological differences between the sexes, but can be extended to any biologically-related process that varies between males and females. More recently the term has been applied to genetic alterations, including gene knockouts, that result in different phenotypes in males and females. The process of meiosis exhibits extensive sexual dimorphism, both in terms of temporal and biological differences, and in terms of the meiotic phenotypes of male and female mice derived from various gene targeting experiments (Tables 1 and 2). For example, in females, the entire complement of germ cells proceeds through meiosis I semi-synchronously during embryonic development. Pro- phase I is mostly completed during foetal development and oocytes then enter dictyate arrest. The oocytes then remain quiescent until after female sexual maturation, when a select number of oocytes are recruited at each oestrous cycle to resume meiosis. They complete the first meiotic division, extruding the first polar body and arrest again at metaphase II. Upon fertilization, the second meiotic division is completed and the second polar body is extruded (reviewed by Handel \& Eppig 1998).

In contrast to the situation in females, meiosis in males is an entirely postnatal event (Handel \& Eppig (1998) (Table 1). Germ cells enter meiosis prior to puberty, and gametogenesis continues in waves throughout adult life, recruiting a new population of germ cells to enter meiosis during each wave of spermatogenesis. This difference is reflected in the extended reproductive life of most male mammals relative to their female counterparts.

Despite the overt temporal differences in the onset of prophase I between male and female meiocytes, the 
Table 1 Basic morphological and biological differences between male and female meiosis.

\begin{tabular}{|c|c|c|}
\hline & Female meiosis & Male meiosis \\
\hline Timing & $\begin{array}{l}\text { Prophase I occurs during embryonic development, } \\
\text { metaphase I and beyond occur after puberty }\end{array}$ & $\begin{array}{l}\text { Meiosis commences at puberty and proceeds without } \\
\text { interruptions }\end{array}$ \\
\hline Synchrony & $\begin{array}{l}\text { Entire population of oocytes go through meiosis } \\
\text { synchronously until dictyate arrest and then a } \\
\text { select group of oocytes are recruited to complete } \\
\text { meiosis I and II after puberty }\end{array}$ & $\begin{array}{l}\text { Spermatocytes go through meiosis in waves continuously } \\
\text { throughout adult life. New spermatocytes are recruited } \\
\text { from mitotically proliferating spermatogonia for each } \\
\text { wave }\end{array}$ \\
\hline Gamete production & $\begin{array}{l}1 \text { haploid oocyte produced ( } 2 \text { polar bodies } \\
\text { extruded) from each meiotic event. Usually } \\
1 \text { oocyte is ovulated at a time }\end{array}$ & $\begin{array}{l}4 \text { haploid spermatocytes produced from each meiotic } \\
\text { event. Millions of sperm per ejaculate }\end{array}$ \\
\hline Arrest periods & $\begin{array}{l}\text { Two: } \\
\text { 1. dictyate arrest (after prophase I and until } \\
\text { recruitment for maturation) } \\
\text { 2. metaphase II arrest (lasts until fertilization) }\end{array}$ & None \\
\hline Morphology & $\begin{array}{l}\text { Each ooctye is isolated from neighboring } \\
\text { ooctyes and is surrounded by supporting } \\
\text { cells in the ovary (granulosa cells) }\end{array}$ & $\begin{array}{l}\text { Spermatocytes are joined by gap junctions and } \\
\text { surrounded by supporting cells in the testis (sertoli and } \\
\text { lydig cells) }\end{array}$ \\
\hline Aneuploidy rate (of gametes) & $\begin{array}{l}\text { Mice }-1-2 \% \\
\text { Humans }- \text { as high as } 25 \%\end{array}$ & $\begin{array}{l}\text { Mice }-1-2 \% \\
\text { Humans }-2 \%\end{array}$ \\
\hline
\end{tabular}

processes of recombination and synapsis appear to be largely conserved between the sexes, both in the cytogenetic appearance of prophase I and in terms of the pathways that regulate these processes. However, there are also significant differences in the relative success rates of meiosis in males and females. This is best exemplified in humans, in which oocyte aneuploidy rates are as high as $25 \%$, much elevated from the $2 \%$ generally seen in sperm (Hassold \& Hunt 2001). The importance of prophase I events for ensuring accurate chromosome segregation is underscored by the observation that for certain chromosomes up to $100 \%$ of these aneuploidies are the result of chromosome non-disjunction during the first meiotic division (Hassold \& Hunt 2001).

Thus, it has been proposed that the cellular mechanisms that regulate and monitor prophase I events during mammalian meiosis are more stringent in males than in females, and that the failure of such monitoring processes (commonly known as 'checkpoints') in females is responsible for the increased rate of meiosis I non-disjunction. This hypothesis has been supported by many different mouse mutants for meiotic regulatory genes and these will be discussed and examined herein. Ultimately, the aim of this review is to gain insight into the molecular basis for male and female meiotic differences and to explore the reasons for this sexual dimorphism. This will provide us with a greater understanding of the etiology of human non-disjunction and perhaps may reveal important evolutionary mechanisms for the sexual dimorphism that exists in mammalian meiosis. Our discussion is mostly limited to meiosis I, since it is this stage in which most of the non-disjunction events are thought to arise in human oocytes (Hassold \& Hunt 2001), but with the acknowledgement that meiotic events outside this stage are also subject to considerable variability between the sexes.

\section{Prophase I events ensuring proper synapsis and double stranded break repair}

The key events in prophase I include the alignment of, and physical association between, homologous chromosomes, the latter being a combined result of recombination events between homologous DNA sequences and the protein-driven events of the SC. In males, mutations causing synaptic and/or recombination failure often lead to complete meiotic failure, preventing progression past a zygotene or pachytene-like stage and resulting in widespread apoptosis of spermatocytes and infertility due to the absence of mature spermatozoa. In females, the same mutations may also lead to synaptic defects but can result in different meiotic phenotypes. Females display a spectrum of phenotypes, ranging from reduced fertility and embryo loss (presumably due to aneuploid embryos) to complete infertility and ovarian dysgenesis (Table 2).

\section{Features of the synaptonemal complex and cohesin core formation}

The synaptonemal complex (SC) mediates DSB resolution events leading to recombination, either by stabilizing a structurally defined intermediate or by acting as a docking site for key regulatory proteins. These include proteins that are engaged in the physical process of recombination, cell cycle regulators that monitor these events, and checkpoint proteins that assess the integrity of the DNA and can signal to the checkpoint machinery to advance or to slow down progression through meiosis. This latter group is also responsible for initiating apoptotic mechanisms in the face of extensive or irreparable DNA damage.

Interesting sex differences are apparent during SC formation in mice. These include SC length, which is twice as long in females as in males. Other variations include the retention of SC proteins at the centromeres through anaphase II in males while in females all traces of 
Table 2 Functions and mutant phenotypes of senes necessary for meiotic progression.

\begin{tabular}{|c|c|c|c|c|c|}
\hline Category & $\begin{array}{l}\text { Gene } \\
\text { (mutation) }\end{array}$ & Meiotic function & Male phenotype & Female phenotype & References \\
\hline \multirow[t]{2}{*}{ SC Components } & Sycp3 (-/-) & $\begin{array}{l}\text { SC formation, Homolog pairing, scaffold for } \\
\text { recombination events }\end{array}$ & $\begin{array}{l}\text { Sterile-failure to proceed past } \\
\text { zygotene-like stage }\end{array}$ & $\begin{array}{l}\text { Sub-fertile (possibly due to } \\
\text { aneuploid embryos) }\end{array}$ & $\begin{array}{l}\text { Kolas et al. (2004) } \\
\text { Yuan et al. (2000) }\end{array}$ \\
\hline & Fkbp6 (-/-) & $\begin{array}{l}\text { SC component-male specific role in synapsis, } \\
\text { other functions unclear }\end{array}$ & $\begin{array}{l}\text { Sterile-failure to proceed past } \\
\text { zygotene-like stage }\end{array}$ & Fertile & Crackower et al. (2003) \\
\hline \multirow[t]{2}{*}{ Cohesins } & $\begin{array}{l}\text { Smc1Beta } \\
(-/-)\end{array}$ & sister chromatid cohesion & $\begin{array}{l}\text { Sterile-failure to proceed past } \\
\text { zygotene-like stage }\end{array}$ & Sterile-absence of follicles & Revenkova et al. (2004) \\
\hline & $\operatorname{Rec8}$ (mei8) & sister chromatid cohesion & $\begin{array}{l}\text { Sterile-failure to proceed past } \\
\text { zygotene-like stage }\end{array}$ & $\begin{array}{l}\text { Sterile-oocyte depletion, ovarian } \\
\text { dysgenesis }\end{array}$ & Bannister et al. (2004) \\
\hline Mismatch Repair & Msh4 (-/-) & $\begin{array}{l}\text { Intermediate-stage recombination resolution } \\
\text { pathway, Homology Search }\end{array}$ & $\begin{array}{l}\text { Sterile-failure to proceed past } \\
\text { zygotene-like stage }\end{array}$ & $\begin{array}{l}\text { Sterile-oocyte depletion, } \\
\text { ovarian dysgenesis }\end{array}$ & Kneitz et al. (2000) \\
\hline \multirow[t]{4}{*}{ Proteins } & $\operatorname{Msh} 5(-/-)$ & $\begin{array}{l}\text { Intermediate-stage recombination resolution } \\
\text { pathway, Homology Search }\end{array}$ & $\begin{array}{l}\text { Sterile-failure to proceed past } \\
\text { zygotene-like stage }\end{array}$ & $\begin{array}{l}\text { Sterile-occyte depletion, ovarian } \\
\text { dysgenesis }\end{array}$ & Edelmann et al. (1999) \\
\hline & Pms2 (-/-) & Mismatch repair-specifics unclear & $\begin{array}{l}\text { Sterile-slow diminuation of } \\
\text { spermatocytes, residual numbers } \\
\text { of abnormal spermatozoa }\end{array}$ & Fertile & Baker et al. (1995) \\
\hline & Mlh1 (-/-) & $\begin{array}{l}\text { Late-stage recombination resolution, } \\
\text { Chiasmata/crossover formation }\end{array}$ & Sterile-failure at metaphase I & $\begin{array}{l}\text { Failure-some ocytes are fertilization } \\
\text { competent and reach the } \\
\text { 2-cell zygote stage }\end{array}$ & $\begin{array}{l}\text { Edelmann et al. (1996) } \\
\text { Woods et al. (1999) } \\
\text { Eaker et al. (2002) }\end{array}$ \\
\hline & Mlh3 (-/-) & $\begin{array}{l}\text { Late-stage recombination resolution, } \\
\text { Chiasmata/crossover formation }\end{array}$ & Sterile-failure at metaphase I & $\begin{array}{l}\text { Failure-some oocytes are fertilization } \\
\text { competent and reach the } 2 \text {-cell } \\
\text { zygote stage }\end{array}$ & Lipkin et al. (2002) \\
\hline Gene Expression & $M v h(-/-)$ & $\begin{array}{l}\text { Postranslational gene expression } \\
\text { regulation-RNA Helicase }\end{array}$ & $\begin{array}{l}\text { Sterile-spermatogenic failure at } \\
\text { leptotene/zygotene }\end{array}$ & Fertile & Tanaka et al. (2000) \\
\hline \multirow[t]{3}{*}{ Regulators } & Mili (-/-) & $\begin{array}{l}\text { Postranslational gene expression } \\
\text { regulation-RNA processing }\end{array}$ & $\begin{array}{l}\text { Sterile-spermatogenic failure at } \\
\text { zygotene/pachytene }\end{array}$ & Fertile & $\begin{array}{l}\text { Kuramochi-Miyagawa et al. } \\
\text { (2004) }\end{array}$ \\
\hline & Miwi (-/-) & $\begin{array}{l}\text { postranslational gene expression } \\
\text { regulation-RNA processing }\end{array}$ & $\begin{array}{l}\text { Sterile-spermatogenic arrest at } \\
\text { round spermatid stage }\end{array}$ & Fertile & Deng \& Lin (2002) \\
\hline & Ovol1 (-/-) & $\begin{array}{l}\text { Transcriptional gene expression } \\
\text { regulation-Zinc Finger Transcription }\end{array}$ & $\begin{array}{l}\text { Sterile-spermatogenic arrest at } \\
\text { pachytene }\end{array}$ & Fertile & Dai et al. (1998) \\
\hline Cell Cycle & $\begin{array}{l}\text { Cyclin } A 1 \\
(-/-)\end{array}$ & $\begin{array}{l}\text { Prophase I to metaphase I transition-via } \\
\text { MPF activation }\end{array}$ & $\begin{array}{l}\text { Sterile-spermatogenic failure } \\
\text { at metaphase I }\end{array}$ & Fertile & Liu et al. (1998) \\
\hline Regulators & $\begin{array}{l}C d c 25 b \\
(-/-)\end{array}$ & $\begin{array}{l}\text { Release from Dictyate Arrest via MPF } \\
\text { activation and possible function as a } \\
\text { steroid receptor cofactor }\end{array}$ & Fertile & $\begin{array}{l}\text { Sterile-failure to resume meiosis } \\
\text { after dityate arrest }\end{array}$ & Lincoln et al. (2002) \\
\hline \multirow[t]{4}{*}{$\begin{array}{l}\text { DSB } \\
\text { formation/repair }\end{array}$} & Spo11 (-/-) & DSB formation in early prophase I & $\begin{array}{l}\text { Sterile-failure to proceed past } \\
\text { zygotene-like stage }\end{array}$ & $\begin{array}{l}\text { Sterile-oocyte depletion, ovarian } \\
\text { dysgenesis }\end{array}$ & $\begin{array}{l}\text { Romanienko \& Camerini- } \\
\text { Otero (2000) } \\
\text { Baudat et al. (2000) } \\
\text { Klein et al. (2002) }\end{array}$ \\
\hline & $\operatorname{Dmc1}(-/-)$ & $\begin{array}{l}\text { ssDNA binding protein-DSB repair } \\
\text { pathway }\end{array}$ & $\begin{array}{l}\text { Sterile-failure to proceed past } \\
\text { zygotene-like stage }\end{array}$ & $\begin{array}{l}\text { Sterile-failure to proceed past } \\
\text { pachytene }\end{array}$ & $\begin{array}{l}\text { Pittman et al. (1998) } \\
\text { Yoshida et al. (1998) }\end{array}$ \\
\hline & mei1 & $\begin{array}{l}\text { Possible functional partner of Spo11 } \\
\text { aiding in DSB formation }\end{array}$ & $\begin{array}{l}\text { Sterile-failure to proceed past } \\
\text { zygotene-like stage }\end{array}$ & $\begin{array}{l}\text { Sterile-inability to resume meiosis } \\
\text { and complete the first meiotic division }\end{array}$ & Libby et al. (2003) \\
\hline & $\begin{array}{l}\text { Brca1 }(\text { Brca1 } \\
\left.-{ }_{-/-} 53^{-/-}\right)\end{array}$ & Role in DSB repair pathway-specifics unclear & $\begin{array}{l}\text { Sterile-failure to proceed past } \\
\text { zygotene-like stage }\end{array}$ & $\begin{array}{l}\text { Sterile-primary and secondary folicles } \\
\text { formed (oocytes reach dictyate } \\
\text { arrest) }\end{array}$ & $\begin{array}{l}\text { Cressman et al. (1999) } \\
\text { Xu et al. (2003) }\end{array}$ \\
\hline
\end{tabular}




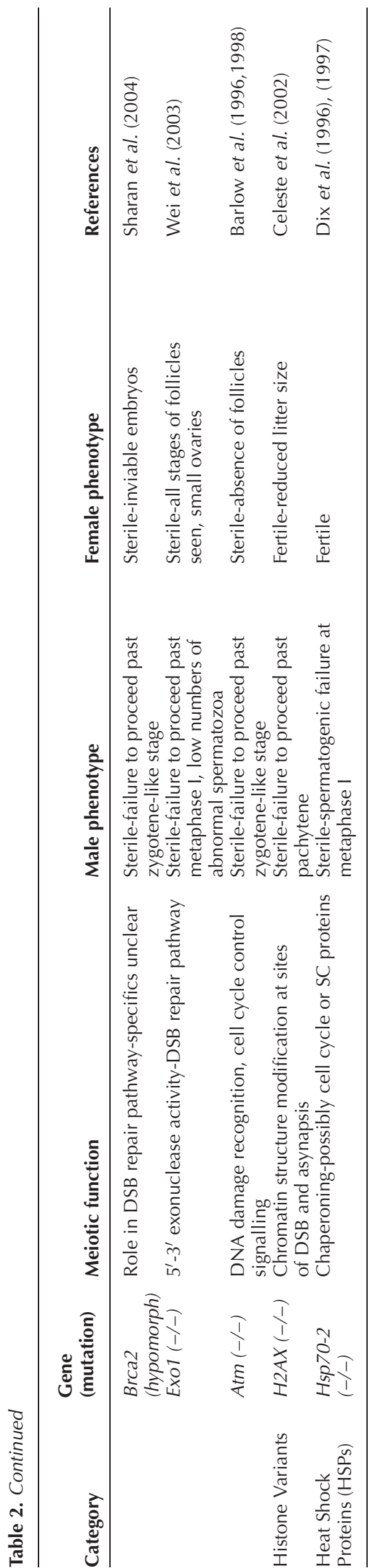

the SC have disappeared by the onset of the first meiotic division (Hodges et al. 2001). Also, timing differences exist in SC formation in relation to DSB formation/resolution events (Roig et al. 2004), and these differences combined may play a significant role in defining male and female meiosis as distinct processes. As observed in other meiotic organisms such as Saccharomyces cerevisiae, abnormalities in SC formation lead to defects in synapsis as well as the recombination pathway (reviewed by Page \& Hawley (2004)). Similar to mice defective in DSB formation, mice with SC abnormalities also display sexdependent phenotypes as a result of synaptic defects.

SYCP3 is the major LE/AE component of the mammalian synaptonemal complex. SYCP3 is involved in events including specificity of chromatin loop attachment to the SC, synapsis (but not homolog juxtaposition), chiasmata formation, cohesin core integrity, chromosome condensation and recombination (Yuan et al. 2000, Yuan et al. 2002, Kolas et al. 2004, Liebe et al. 2004, Kouznetsova et al. 2005). Syср $3^{-1-}$ mice display infertility in males and reduced fertility in females. Males display small testes and seminiferous tubules as a consequence of their failure to proceed past the zygonema stage of prophase I. Spermatocytes from Syср $3^{-1}$ males exhibit severe synaptic defects at this stage, resulting in checkpointmediated apoptosis. Females are subfertile due to mild synapsis defects and defective chromosomal segregation, both resulting in loss of aneuploid embryos and declining fertility with advanced age (Yuan et al. 2002).

These observations suggest that the requirement for SYCP3 in male meiocytes is more stringent than in females. Indeed, SYCP3 is retained on meiotic chromosomes in mouse spermatocytes, particularly at the centromere, through metaphase I (Moens \& Spyropoulos, 1995), while it is lost from oocytes at dictyate (Hodges et al. 2001b, Kolas et al. 2005). This suggests a requirement for SYCP3 in the maintenance of centromere cohesion in males, but not females. This suggestion has been refuted by observations that centromere cohesion is unaffected in Syсp3 $3^{-1}$ and/or Sycp2 $2^{-1}$ spermatocytes treated with okadaic acid, a phosphatase inhibitor that accelerates entry in to metaphase I (Kouznetsova et al. 2005). Alternatively, the relative fertility of $S y c p 3^{-/}$females could indicate functional redundancy in female SC components, allowing other AE/LE proteins to compensate for SYCP3 in synapsis. Either way, it is interesting to note that, despite the increased SC length in female meiocytes, loss of key SC components in oocytes does not result in the severe meiotic disruption observed in males.

Cohesins are the proteins that hold sister chromatids together during both meiosis and mitosis, as well as holding homologous chromosomes together in meiosis. In meiosis, they are essential for proper recombination, completion of synapsis, and chiasmata formation. Cohesins possibly achieve these functions by acting as a scaffold for recombination resolution events. Mutation of the meiosis specific core cohesin, Smc1 $\beta$, causes defects in meiotic 
nodule maturation, chromatin configuration, SC length, SC integrity (i.e. fragmentation), synapsis and maintenance of sister chromatid cohesion resulting in both male and female sterility (Revenkova et al. 2004). Male meiosis is blocked at the pachytene stage, resulting in apoptosis. Female meiosis in Smc1 $\beta$ nulls exhibit prophase I defects similar to male meiosis, but a proportion of the ooctyes complete prophase I and reach dictyate arrest (see Revenkova \& Jessbergen 2005). In fact, some Smc1 $\beta^{-/-}$oocytes complete the first meiotic division in culture, albeit with increased rates of errors (Revenkova et al. 2004).

FKBP6 is a member of the FKBP family of proteins which bind the immunosuppressant drug FK506 and have a number of functions, including steroid receptor binding and chaperoning. FKBP6 is a novel SC component in both male and female rodents, but its function remains unclear. $\mathrm{Fkbp6}^{-/-}$mice exhibit male sterility associated with pairing defects and spermatogenic failure in early prophase I, but females are fertile with no observed abnormalities in oogenesis (Crackower et al. 2003). This implicates a malespecific involvement in chromosome pairing and synapsis for Fkbp6 and/or an involvement in a male-specific synapsis checkpoint at prophase I. One possible mechanism for the sex-specificity of FKBP6 is through the testis specific heat shock protein (HSP)70-2 protein, as FK506 family members involved in steroid receptor trafficking have been shown to interact with HSP90 and HSP70 (Tai et al. 1992, Radanyi et al. 1994, Reddy et al. 1998). This presents the intriguing possibility that in males FKBP6 interacts with HSP70-2, possibly aiding in the chaperoning, mediation or recruitment of cell cycle or SC components that could trigger a checkpoint when disrupted.

In summary, despite the fact that the SC is present in meiocytes from male and female mice, and that the SC length is longer in female germ cells than in males, it appears that the requirements for SC formation and function are different between the sexes. The exact nature of this difference remains to be determined, but it is interesting to note that the structural functions for the SC are not changed, and that no substitute proteins have been found to account for the phenotypic differences in male/female mice lacking SC and cohesin components. Clearly, this speaks to our lack of understanding of how SC formation is linked to prophase I events affecting chromosome segregation, a gap that is likely to be filled by further genetic analyses of the type described above.

\section{Double stranded break formation and repair}

The creation of double stranded breaks (DSBs) in early meiotic prophase I is a conserved feature of meiosis. One notable exception is Drosophila melanogaster males, where prophase I events, including homolog pairing and segregation, proceed correctly with no reciprocal recombination or SC formation (McKee 1998, Hawley 2002, Vazquez et al. 2002). This suggests the existence of an SCindependent mechanism, termed distributive segregation
(Page \& Hawley, 2004), for ensuring proper chromosome segregation. In mammals disrupting DSB formation impairs the homolog recognition process (McKee 2004, Svetlanov \& Cohen 2004), indicating that they play a pivotal role in this meiotic event. In fact, DSBs are essential for synapsis in most organisms, with the exception of Caenorhabditis elegans and both sexes of D. melanogaster (reviewed by Page \& Hawley (2004)).

Despite the conservation of meiotic recombination from yeast through humans, there remains a significant level of variability amongst organisms, and even between different sexes of the same organism. Interestingly, although recombination is implemented by nearly identical machinery in both sexes, there is consistently more recombination in human and mouse females compared to males in addition to recombination events being more distally located in males (reviewed by Hassold et al. (2000)). One major factor influencing this is the extended length of female SCs, which are about two times longer than male SCs despite the equivalent size of their genomes (Tease \& Hulten 2004). In addition to the observed sex differences in wildtype DSB formation and repair, disturbances in this pathway also result in sex dependent phenotypes due to the distinct male and female responses to asynapsed or improperly synapsed chromosomes.

A key player in the meiotic DSB pathway is SPO11, which is expressed specifically in prophase I of meiosis and is proposed to be the enzyme responsible for creating DSBs, via a type II DNA topoisomerase-like activity (Keeney et al. 1997). SPO11 performs this function in all meiotic organisms that undergo reciprocal recombination. Additionally, SPO11 acts with the aid of multiple functional partners that are well-defined in yeast and other organisms, and that are beginning to be elucidated in mammals (Romanienko \& Camerini-Otero 2000, Klein et al. 2002, Bannister \& Schimenti 2004, Kolas \& Cohen 2004, Richardson et al. 2004). Genetic studies have also discovered at least one mammalian specific partner for SPO11, which is truncated in the mei1 mouse mutant (Libby et al. 2002). Following SPO11 removal from the chromosomes, possibly aided by the aforementioned functional partners, DSB sites are further processed to become 3' overhangs. The overhangs subsequently become the substrate for the Rec A homolog single stranded binding proteins, DMC1 and RAD51, facilitating strand invasion and double Holliday junction formation (Masson \& West 2001).

DMC1 and RAD51 localize to meiotic chromosomes at distinct foci, called meiotic nodules - proteinacious structures present on the SC which change dynamically in number and composition throughout prophase I (Plug et al. 1998, Baarends \& Grootegoed 2003). Meiotic nodules are also the site of localization for proteins involved in the downstream events of DSB processing, resulting in the formation of reciprocal and non-reciprocal recombination events. Meiotic nodules are evident as early as leptonema and persist through pachynema, their frequency 
and location being indicative of the number of DSB events and ultimately, it is thought, giving rise to the mature population of crossovers (reviewed by Zickler \& Kleckner (1999)). The number of DSBs is highest at leptonema and zygonema, when the DSB count is approximately 10 -fold higher than the final chiasma count (greater than 300 and 20-30 respectively). It is interesting to note that the early meiotic nodule count is similar in male and female germ cells despite the fact that female chiasma counts are always higher, again illustrating the strict regulation of meiotic nodule dynamics in both males and females.

As DSBs are further processed, RAD51 and DMC1 are lost from the meiotic nodules, concomitant with the onset of synapsis, and are replaced with downstream components of the recombinogenic machinery. Many of these protein components are highly conserved across all SCcontaining organisms, but in higher organisms additional components are present such as Brca1 (breast cancer 1) and Brca2 (breast cancer 2) indicating the development of additional functions for meiotic nodules in the regulation or implementation of crossover events.

Mouse mutants harboring targeted disruptions of DSB formation/repair pathway components illustrate typical sex-differential phenotypes associated with DSB pathway disturbances (Table 2). Spo $11^{-/-}$male mice are sterile due to a failure to progress past zygonema and display severe synaptic defects. Restoration of DSBs in $\mathrm{Spo1}^{-/-}$male spermatocytes by cisplatin partially rescues meiosis, allowing the cells to progress through zygonema at least to the point of accumulating RAD51 at the meiotic nodules (Romanienko \& Camerini-Otero 2000). Females are also sterile, with oocyte defects becoming apparent as early as embryonic day 15 , indicating progression through to zygonema. While some oocytes progress through dictyate arrest, oocyte depletion and ovarian dysgenesis are observed postnatally (Baudat et al. 2000, Romanienko \& Camerini-Otero 2000), suggesting oocyte loss during dictyate. Thus, while DSBs are essential for recombination in both sexes, elimination of the enzyme thought to be responsible for DSB formation results in a stringent loss of spermatocytes in zygonema while oocytes progress beyond pachynema.

The mei1 mutation was identified in a screen for meiotic defects following ENU mutagenesis. This mutation results in deficiencies in the DSB repair pathway, and yields similar phenotypic responses to that seen in Spo11 null mice. The absence of the phosphorylated form of histone $\mathrm{H} 2 \mathrm{AX}(\gamma \mathrm{H} 2 \mathrm{AX})$ on chromosomes in leptonema, and the failure to accumulate RAD51-positive foci in zygonema, indicates that DSBs do not form in mei1 mutants (Libby et al. 2003), raising the possibility that the gene product mutated in mei1 mice acts upstream of SPO11 or is a co-factor in SPO11-mediated events. Male mei1 mutant mice are sterile, displaying synaptic defects and failure of spermatogenesis to progress past zygonema, a phenotype that is partially rescued by cisplatin treatment (Libby et al. 2003).
Female mei1 mice are also sterile, displaying similar synaptic defects (Libby et al. 2002). However, adult ovaries contain oocytes in dictyate arrest, with follicular structures reminiscent of early primordial to antral stages. When matured in vitro, some oocytes from mei1/mei1 females are capable of progressing through $\mathrm{MI}$ and releasing a polar body, only to succumb to meiotic defects in meiosis II. The majority of oocytes, however, display spindle errors and congression failure at $\mathrm{Ml}$, resulting in improper chromosome segregation at the first division (Libby et al. 2002, Libby et al. 2003).

Other components of meiotic nodules such as the Brca genes appear to serve important functions in the meiotic DSB repair pathway among their other roles in genome stabilization. Brca1 and Brca2 mutations predispose individuals to breast and ovarian cancer (Easton et al. 1995, Wooster et al. 1995, Hopper et al. 1999). Brca1 has been shown to be involved in DNA damage repair and crossover during male meiosis in mice. (Xu et al. 2003). The Brca ${ }^{-/} \mathrm{p} 3^{-/-}$double mutant has provided insight into the meiotic role of Brca1 as Brca1 ${ }^{-1-}$ embryonic lethality can be partially rescued by p53 deletion. These mice display male sterility due to spermatogenic failure prior to pachynema. Females have both primary and growing follicles, indicating that oocytes, unlike spermatocytes, progress through pachynema and reach dictyate arrest (Cressman et al. 1999). Additionally, BRCA1 co-localizes with ataxia telangiectasia mutated (ATM) and $\gamma \mathrm{H} 2 \mathrm{AX}$ through zygonema, localizing to unsynapsed chromosomes, and disappearing after synapsis. BRCA1, ataxia telangiectasia related (ATR) and $\gamma \mathrm{H} 2 \mathrm{AX}$ are thought to play a role in DNA repair in somatic cells, meiotic sex chromosome silencing $(\mathrm{MSCl})$, transcriptional silencing of unsynapsed autosomes and perhaps detection of asynapsis (Turner et al. 2004, Turner et al. 2005).

Brca2 also appears to be involved in DSB repair, colocalizing with RAD51, as it does in somatic cells. While the meiotic role of BRCA2 remains unclear, decreased expression of $\mathrm{Brca} 2$ results in male and female sterility. Spermatocytes display synaptic defects and failure to proceed past zygonema, while oocytes are capable of producing embryos, but these are mostly inviable (Sharan et al. 2004).

\section{Mutant mice with uncertain or mildly sexually dimorphic recombinogenic phenotypes}

In addition to the previously discussed meiotic mutants that exhibit sexually dimorphic phenotypes, there are other mutants which may exhibit some degree of difference in male and female gametogenesis. In some cases, the meiotic phenotype of mutant females has not been studied in enough depth to confirm a sexually dimorphic response to a given mutation, but in other cases there are temporal and morphological differences that present technical difficulties for comparison between the sexes. These include mouse mutants for the DNA repair genes Msh4, Msh5, Dmc1, Atm, and for the cohesin Rec8. Msh4 
and Msh5 are mammalian homologs of the Escherichia coli Mut $\mathrm{S}$ mismatch repair gene. The meiotic mismatch repair proteins they encode function as a heterodimer in the recombination pathway and possibly also aid in homolog searching during leptonema since null mice display defects in both pairing and synapsis. REC8, like $S M C 1 \beta$, is a meiosis specific cohesin. DMC1 is a meiosis specific homolog of the E. coli RECA (Recombination A) protein. It is a component of meiotic nodules and plays a role in resolving DSBs and homology searching (Masson \& West 2001). In meiosis, DMC1 functions with RAD51, a ubiquitous RECA homolog, to facilitate recombination (Shinohara et al. 1997). This need for two RECA homologs in meiosis, while RAD51 alone suffices in somatic cells, suggests a need for meiosis specific control of recombination events.

Atm is the murine homolog of the gene mutated in the human disorder ataxia telangiectasia (AT; Boder 1975). $\mathrm{Atm}^{-/}$mice exhibit many of the defects associated with AT including neurodegeneration, immunodeficiency, cancer predisposition and infertility (Xu et al. 1996), illustrating the role of ATM in DNA integrity and stability. ATM, and its related protein, ATR, are members of the PI3-kinase family of proteins that recognize DNA damage and signal to the appropriate repair machineries. ATM activates many of the proteins involved in DSB repair, including the RAD50/MRE11/NBS1 complex and the BRCA1/2 checkpoint proteins (reviewed by Lavin et al. (2005)).

Both ATM and ATR localize to SCs in prophase I. ATR associates predominantly with unpaired axes from leptonema to pachynema and is mostly gone by mid-pachynema (Barlow et al. 1998). ATM localization appears to lag behind ATR somewhat, appearing along asynapsed and synapsed meiotic chromosomes from late zygonema through to pachynema (Plug et al. 1997). The localization of both proteins to oocyte SCs has not been reported, although Barlow et al. have shown immunohistochemical labeling of oocytes from postnatal mouse ovaries with anti-ATM antibody (Barlow et al. 1998).

They also note that oocyte loss in $\mathrm{Atm}^{-1}$ females begins as early as embryonic day 16.5 and follows a similar time course to that seen in Spo11 $11^{-/}$females. By 11 days postpartum, ovaries are devoid of follicles indicating that oocytes die prior to or during dictyate arrest (Barlow et al. 1996, Barlow et al. 1998). This is in contrast to spermatocytes which fail to proceed past zygonema.

Mutations in Dmc1, Msh4, Msh5, and Rec8 result in male sterility due to spermatogenic failure at the zygotene to pachytene transition. In all cases, chromosomes fail to synapse properly, resulting in univalent chromosomes and/or non-homologous synapsis. Oocytes progress through leptonema and early zygonema, before initiating synapsis in late zygonema (Pittman et al. 1998, Yoshida et al. 1998, Edelmann et al. 1999, Kneitz et al. 2000, Bannister et al. 2004). Meiotic failure at some later point is indicated by the observation that these female mice are all sterile, but the exact stage of meiotic disruption is vari- able and often unclear. The degree of synapsis observed in ooctyes from $\mathrm{Msh}^{-/-}$and Msh5 $5^{-/}$females is significantly greater than that seen in their male counterparts, but never reaches full synapsis of even single chromosome pairs (P E Cohen and W Edelmann (Albert Einstein College of Medicine, Bronx, NY, USA), unpublished observations). At the cellular level the oocytes from $\mathrm{Msh}^{-/-}$and $\mathrm{Msh}^{-{ }^{--}}$ females persist through birth, but are almost completely absent by day 6 postpartum (Edelmann et al. 1999, Kneitz et al. 2000). Interestingly this presents a disparity between the stage of meiotic failure and the stage of oocyte loss. According to early studies of meiosis in wildtype mouse fetal ovaries, entry into pachynema is evident from embryonic day 16, with the majority of oocytes having passed through zygonema by embryonic day 17 (Evans et al. 1982). By day 1 postpartum, greater than $90 \%$ of wildtype oocytes have entered diplotene (Evans et al. 1982). Clearly, therefore, the meiotic disruption in Msh4 ${ }^{-/}$ and $\mathrm{Msh}^{-}{ }^{-}$mice occurs between embryonic days 16 and 18 , and yet oocyte loss is not observed until shortly after birth. This would suggest either that earlier stages of prophase I are prolonged in the absence of these MutS homologs, or that the detection of failed synapsis events is not triggered immediately, perhaps as a result of a gonad-wide monitoring system for tracking ovarian development, or by cell-intrinsic checkpoint systems that activate at birth.

$D m \mathrm{C1}^{-/}$oocytes are also present around birth in similarly reduced numbers to that in Spo $11^{-1-}$. However, unlike the Spo $11^{-/}$oocytes, those from $D m c 1^{-/}$females appear to be degenerating already at this point, indicating that oogenic failure occurs at a stage prior to or around dictyate arrest (Pittman et al. 1998). Thus $D m c 1^{-1}$ females display earlier oocyte defects than Spo $11^{-/-}$females, leading to an increase in the severity of ovarian degeneration compared to Spo11 $11^{-1}$. The same is true for Msh4 and Msh5 null mice, suggesting that the severity of the ovarian phenotype in these three cases could depend on the presence or absence of unrepaired DSBs. Supporting this, $\mathrm{Atm}^{-1}$ and Msh5 $5^{-1-}$ oocytes, which contain unrepaired DSBs, display similar phenotypes to $D m c 1^{-1}$ females.

Eliminating DSB formation (via Spo11 mutation) in $\mathrm{Dmcl}^{-1}$, Msh5 ${ }^{-1-}$, and $\mathrm{Atm}^{-1}$ mice rescues the observed ovarian dysgenesis phenotype and results in a similar phenotype to Spo11 single mutants (Di Giacomo et al. 2005). Thus, in an apparent DNA damage checkpoint response, unrepaired DSBs induce oocyte degeneration prior to or at the dictyate stage which results in severe ovarian degeneration (Fig. 2). In the absence of DSBs, this checkpoint is not activated and oogenic failure occurs at a later stage as a result of failure in events in the recombination pathway (i.e. homology search, chiasmata formation), possibly due to these defects resulting in an inability to resume meiosis after dictyate arrest and/or activation of the spindle checkpoint.

REC 8 and SMC1 $\beta$ are both meiosis specific cohesins, which appear to perform similar functions in meiosis, including sister chromatid cohesion. This high degree of 


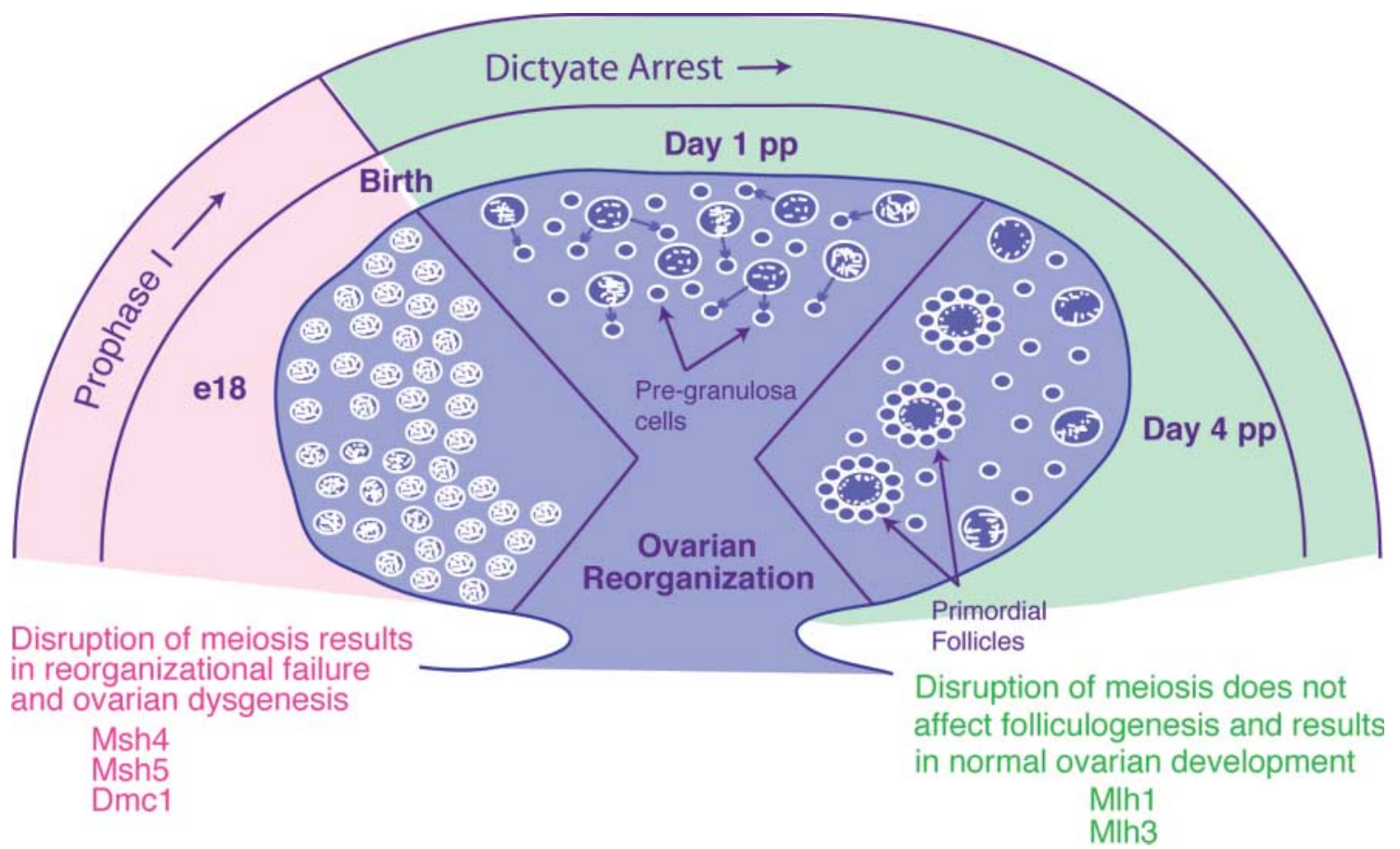

Figure 2 Meiotic progression and ovarian reorganization events from late prophase I through to day 4 postpartum (pp). Examples of genes which when mutated result in disruption of ovarian reorganization, as well as those that do not affect ovarian development are given. e18; embryonic day 18.

functional similarity indicates that mei8 mice, which are Rec8 mutants, could display a similarly sexually dimorphic phenotype to $S m c 1 \beta$ mutants. meis females fail to complete meiosis I and display ovarian degeneration. However, the exact stage of oogenic failure is unclear and it remains to be determined whether the mutation causes a similar meiotic disruption to that seen in meis males. Interestingly, although oocytes from both of these cohesin mutants fail to proceed past meiosis I, mei8 (Rec8 mutant) females display ovarian degeneration similar to $\mathrm{Msh}^{-/}$females, while Smc1 $\beta$ ovaries exhibit milder ovarian degeneration (Edelmann et al. 1999, Kneitz et al. 2000, Bannister et al. 2004, Revenkova et al. 2004).

The Pms2 mismatch repair (MMR) gene functions in meiosis although its exact role remains evasive. Pms2 is a mammalian homolog of the E. coli MutL mismatch repair protein. The yeast Pms2 homolog, Pms1, is involved in DNA repair in response to chromosomal damage and is thought to aid in the repair of heteroduplex DNA (Wang et al. 1999). In mice, Pms2 appears to be involved in mismatch repair in a variety of tissues. Deletion of Pms2 causes increased susceptibility to cancer and male infertility due to synaptic defects and the ensuing slow diminution of spermatocytes and abnormal sperm production (Baker et al. 1995). Females have been reported to be fertile which indicates the presence of a male-specific, although as yet undefined role for Pms2 in prophase I progression.
It is interesting to note that the gonadal degeneration observed in Msh4, Msh5, Dmc1 and Atm null females is not usually present in males bearing the same mutation. This suggests that the presence of germ cells is required for the maintenance of ovarian, but not testicular morphological integrity. The severity of ovarian degeneration is likely to be due to a difference in the stage of oocyte deterioration: oocyte loss prior to dictyate arrest would result in more severe ovarian degeneration than oocyte loss occurring during or after dictyate arrest (Fig. 2). If oocytes reach dictyate and are maintained appropriately, folliculogenesis is initiated and follicles at all stages of development can be observed in the adult ovary. Antral follicles from these ovaries would be visible and these may or may not be capable of exhibiting germinal vesicle breakdown and resumption of meiosis upon natural or induced ovulation. Examples of mice exhibiting this phenotype include Mlh1 and Mlh3 null females, and will be discussed in the next section. In other situations, oocytes enter dictyate arrest in significant numbers (though not necessarily at the same rate as those in wildtype ovaries), but are lost during this arrest phase and never achieve antral follicle stages. In this case, oocytes are incapable of resuming meiosis upon ovulation. If, however, the oocyte population is lost prior to dictyate arrest, the lack of germ cells appears to cause degeneration of the entire ovarian structure, as exemplified by the ovarian phenotype in Msh4 and Dmc1 null females. SPO11 appears to fit into the second category, showing loss of oocytes during 
dictyate arrest. Oocytes from Spo $11^{1 /-}$ females are present at birth, although in reduced numbers, but the oocyte population is reduced drastically around birth, apparently in conjunction with a wave of primordial follicle formation (Baudat et al. 2000, Romanienko \& CameriniOtero 2000). This may indicate that an inability to resume meiosis after dictyate arrest is a major cause of oocyte deterioration, but studies have yet to confirm this.

Whether through involvement in the DSB repair pathway, SC functioning, or an as yet unknown mechanism, the common thread connecting all the factors described in this section is their involvement in recombination and synapsis. If a gene mutation results in synaptic failure, regardless of the underlying mechanism, spermatocytes fail to progress past pachytene, while the extent of oocyte progression in similar mutant backgrounds is variable. Thus, it is not necessarily the processes of DSB formation/ repair or the SC that exhibit sexual dimorphism, rather, it is the monitoring and regulation of prophase I events which elicits a dimorphic response to the deletion of a key gene.

The lengthy list of cases displaying this particular type of dimorphism, clearly demonstrates the presence of a synaptic checkpoint acting during prophase I, specifically at the zygotene to pachytene transition, whose stringency and/or timing is variable between the sexes. In females, this checkpoint appears to be more responsive to DNA damage than synapsis, and the timing also appears to be different and/or delayed. It is possible that the retained ability of oocyte chromosomes to undergo partial synapsis, as in the case of Msh4 and Msh5 null mice, allows then to overcome the immediate effects of the synaptic checkpoint, only to succumb to a DNA damage response at the onset of dictyate arrest. Alternatively, the partial synapsis observed in females may delay the effects of the 'synaptic' checkpoint, allowing oocytes to be retained through until birth. Either way it is plausible that the machinery is similar, at least in this instance, in males and females.

The exact nature of the synaptic and/or DNA damage checkpoint - as well as the metaphase I spindle checkpoint discussed later - remain elusive, although several proteins have properties and/or phenotypes consistent with involvement. The checkpoint could involve SC components, such as FKBP6, specifically required for male synapsis. When disrupted in the absence of other SC components, they could essentially act as a detection mechanism for synaptic failure, resulting in apoptosis. Interestingly, the MutL homologs, MLH1 and PMS2, are possible p53 targets (Chen \& Sadowski 2005), which would make them ideal candidates for checkpoint components, triggering apoptosis through a p53-dependent mechanism. By contrast, the sterility phenotype of $\mathrm{Msh}^{-/-}$ males, which exhibit earlier meiotic arrest than do Mlh1 ${ }^{-/}$ males, is not alleviated by placement on a p53-null background ( $\mathrm{P} E$ Cohen and $\mathrm{W}$ Edelmann (Albert Einstein College of Medicine, Bronx, NY, USA), unpublished observations), suggesting that checkpoint activation prior to pachynema is independent of p53.

\section{The first meiotic division}

The alignment of chromosomes on the metaphase plate and their segregation into daughter cells during the first meiotic division are pivotal in ensuring the ultimate success of meiosis. This is of special interest in relation to human meiosis, as errors in meiosis I are the leading cause of aneuploidies in human conceptuses. Thus studying of the regulation and implementation of this meiotic division is critical to understanding the origins of human aneuploidies. It is important, however, to study not only the first meiotic division per se, but the events leading up to it, including those events already touched upon, and the events of meiotic spindle assembly and chromosome congression.

\section{Translation of prophase I events into accurate segregation at the first meiotic division}

Rates of chromosomal mis-segregation are highly correlated with crossover number and chromosomal placement suggesting that crossover defects may predispose meiocytes to aneuploidy. Male and female mammals, humans in particular, exhibit differences in the frequencies of chiasmata, crossover/recombination events, and aneuploidies, with females exhibiting more crossovers as well as a more uniform crossover distribution along the chromosome, in comparison to the distal localization observed in males (Hassold et al. 2000). Furthermore, MLH1 frequency in human oocytes is highly variable, even between oocytes from the same individual, with a number of different measurements being reported by different groups. Reports of female MLH1 foci and chiasmata number have been quite variable between studies. They range from an average of 42 to 95 (Barlow \& Hulten 1998a, Lynn et al. 2002, Tease et al. 2002, Lenzi et al. 2005), but all consistently show a large variability in the range of foci that is not seen in mice. Male averages for MLH1 foci and chiasmata numbers have been measured at 20 to 50 (Barlow \& Hulten 1996, 1998b, Lynn et al. 2002, Lynn et al. 2004), with less variability from cell to cell. Chiasmata frequency is also consistently lower in human spermatocytes compared to human oocytes, showing less variability, and being located more distally.

The aneuploidy rate for human oocytes has been estimated to be as high as $25 \%$ while in males it is only $2 \%$. In mice the aneuploidy rate is less than $1-2 \%$ and is similar between males and females (Hassold \& Hunt 2001). A factor that may contribute to the high error rate in human females is the observed variation in the number of crossover sites. At least one crossover site is needed per chromosome to ensure proper segregation during the MI. Some measurements indicate that as many as 30\% of oocytes contain fewer than the required $23 \mathrm{MLH} 1$ foci 
(Lenzi et al. 2005). While the fate of these oocytes with low MLH1 foci frequency is unknown, if this were to translate into ultimate crossover events, these oocytes would be at risk for becoming aneuploid. The possibility remains that they may undergo apoptosis prior to reaching meiotic resumption, suggesting perhaps that meioticallydeficient oocytes are cleared from the ovary during folliculogenesis.

\section{Meiosis I division events - the spindle checkpoint and chromosome segregation}

During mitosis, the spindle checkpoint regulating the metaphase to anaphase transition is relatively well defined and appears to be fairly stringent, resulting in anaphase delay until all chromosomes are correctly oriented on the metaphase spindle (Taylor et al. 2004). Many components of the mitotic spindle checkpoint machinery, such as Mad2, Cyclin B, securin, Bub1, and the anaphase promoting complex (APC), also function in a meiotic spindle checkpoint (Brunet et al. 2003, Homer et al. 2005a, $2005 b, 2005 c)$. However, there appear to be differences in this checkpoint between male and female gametes in that there is lower stringency in mammalian females compared to males. Thus, oocytes still proceed through the first meiotic division despite disruptions in spindle and alignment caused by environmental factors and mutations, whereas spermatocytes with similar disruptions undergo apoptosis at metaphase I.

Studies of mouse mutants for the MMR genes, M/h1 and Mlh3, provide some of the most convincing evidence of the meiosis I spindle checkpoint and its sexual dimorphism. MLH1 and MLH3 are homologs of bacterial MutL that function as a heterodimer and which, together with the MutS heterodimer of MSH4 and MSH5, stabilize crossover sites during prophase I (Kolas \& Cohen 2004). $\mathrm{Mlh} 1^{-/}$and $\mathrm{M} / \mathrm{h} 3^{-/}$spermatocytes and oocytes progress normally through most of prophase I, including synapsis, despite only residual numbers of meiotic nodules, indicative of chiasmata, in $\mathrm{Mlh}^{-1}$ mice and their complete absence in $\mathrm{Mlh}^{-1}$ mice (Baker et al. 1996, Edelmann et al. 1996, Lipkin et al. 2002). By diplonema, however, when the SC begins to disassemble and the homologs start to separate, it becomes apparent that the crossovers are no longer intact and the chromosomes fail to remain attached (Baker et al. 1996, Eaker et al. 2002). Spindle abnormalities have been observed in metaphase I oocytes, likely due to defective chromosome attachment (Woods et al. 1999). Mlh $1^{-1-}$ and Mlh3 ${ }^{-/-}$spermatocytes finally succumb to apoptosis at metaphase I, some considerable time after the pairing defects first become apparent. $\mathrm{Mlh} 1^{-/}$and $\mathrm{Mlh} 3^{-/}$females display similar chromosome alignment and spindle formation abnormalities during prophase I but some oocytes are competent to progress far enough to extrude a polar body, reaching the two cell zygote stage (Edelmann et al. 1996, Eaker et al. 2002, Lipkin et al. 2002). Thus, while both sexes of $M / h 1^{-/}$and
Mlh3 \%mice are sterile, spermatocytes fail to progress beyond the metaphase spindle I checkpoint, while some ooctyes can progress to a much later stage despite harboring similar defects, again indicating a reduced stringency for this checkpoint in females.

As described above, the reduced stringency of the female spindle checkpoint at the first meiotic division, is a well-known phenomenon (Brunet et al. 2003). However, there is also evidence that the metaphase I checkpoint for males may be 'leaky' under certain conditions. An example of this was observed in male mice carrying Robertsonian translocations (Eaker et al. 2001). Male mice that are heterozygous for such translocations exhibit an increased frequency of pachytene stage cells, increased misalignment of chromosomes during metaphase I corresponding to elevated levels of apoptosis, a depletion of spermatids, and high levels of aneuploidy in their spermatozoa. Progression through to pachynema is normal in these mice, suggesting either that no synapsis defects occur at zygonema or that the synaptic errors are undetectable by the pachytene checkpoint machinery. By metaphase I, approximately $28 \%$ of cells exhibit premature desynapsis of the translocation chromosomes, with associated misalignment of these chromosomes on the metaphase spindle and apoptotic elimination (Eaker et al. 2001). The remaining $\sim 72 \%$ spermatocytes, however, survive and progress to MII. Two possible explanations exist: firstly, the fact that the non-disjunction involves only the two chromosomes that are involved in the translocation (Eaker et al. 2001) could mean that the asynapsis is not extensive enough to trigger checkpoint mechanisms at metaphase I, or alternatively, it could be that the translocated chromosomes could form a synaptic configuration that is not seen to be defective, resulting in accurate $\mathrm{MI}$ segregation and obviating the need for checkpoint activation. In this latter case, the translocation chromosomes may then become problematic at the second meiotic division, resulting in MII non-disjunction and the subsequent aneuploidy observed in the mature spermatozoa.

Another question that arises from these studies concerns the observation that Robertsonian translocated males do not elicit a checkpoint response at the zygotene to pachytene transition. This may be due to the relatively mild synaptic defects seen as a result of harboring only a single translocation event. Minor cases of asynapsis can occasionally be overcome by mechanisms such as nonhomologous synapsis, auto-synapsis, and synaptic adjustment. The increased frequency of pachytene spermatocytes in Robertsonian translocated males supports this theory, indicating a pachytene delay while translocated chromosomes adopt an appropriate synaptic status. Thus, at both the zygotene to pachytene checkpoint, and at the spindle checkpoint, the ability of chromosomally abnormal spermatocytes to escape checkpoint-associated elimination may reflect their ability to present a suitable synaptic appearance, more than any reduced/impaired stringency of the checkpoint mechanisms. 
Additional evidence for spermatocytes being able to escape a spindle checkpoint even when harboring abnormalities is the $\mathrm{PL} / \mathrm{J}$ strain of mice. In comparison to other strains of mice, such as C57BL/6J, PL/J mice exhibit aberrant chromosome condensation, delayed synapsis at pachynema, and a small but significant decline in MLH1 focus frequency and chiasmata (Pyle \& Handel 2003). As a result, there is a significant increase in aberrant spindle morphology, chromosome misalignment on the metaphase spindle, and increased sperm aneuploidy (Pyle \& Handel 2003). However, spermatocytes do progress through metaphase I and into MII, suggesting that the lower rate of crossing over is not sufficient to disrupt spermatogenesis in all cases.

Similar events are observed in Exo $1^{-1-}$ male mice, who lack the Exonuclease I protein that is thought to act downstream of MLH1 and MLH3 in the MMR pathway. These animals also show a slight decrease in MLH1 focus frequency and subsequent chiasmata formation and also have small numbers of mature sperm within their seminiferous tubules (Wei et al. 2003). Thus reductions in crossing over that do not affect synapsis or the ability to maintain chromosomal bivalent status at metaphase can be tolerated during spermatogenesis and are not likely to lead to checkpoint activation in mice.

\section{Regulation of meiotic gene expression}

During gametogenesis the gene expression program of the cell has to be modified substantially to produce changes in chromatin, organelle content and cell shape. At the same time, the cytogenetic events of prophase I are likely to severely affect the accessibility of the genome to the transcriptional machinery. As such, the nuclear environment in the male must contend with functional conflicts involving the meiotic process and the need to efficiently regulate the expression of spermatogenic genes. Similarly, in females, the requirement for regulated and staged progression through prophase I must be balanced with the need to induce the expression of genes that will invoke dictyate arrest, for example. With this is mind, it is surprising that a disproportionate number of mutations affecting gene regulation cause male-specific, rather than femalespecific, meiotic defects (for example, the transcription factor OVOL1; Dai et al. 1998, Li et al. 2005). One possibility is that female meiosis is not as well-studied as male meiosis because it occurs during embryonic development and is therefore not as accessible for many studies, particularly those involving small-scale biochemical analysis. In addition, large scale mutagenesis screens have discovered a disproportionately large number of male-specific and sex non-differential fertility phenotypes compared to female-specific phenotypes (personal communication with Dr John Schimenti, Cornell University, Ithaca, NY, USA).

At the translational level, male-specific regulators include the Mvh, Mili and Miwi gene products (Fig. 3).
Mvh, Mili, and Miwi mutants all have similar phenotypes, and show functional interactions (Tanaka et al. 2000, Deng \& Lin 2002, Kuramochi-Miyagawa et al. 2004). Mvh is the mouse Vasa homolog gene, a member of the DEADbox family of ATP dependent RNA helicases (Fujiwara et al. 1994). In Drosophila, Vasa is involved in the formation of germ cell precursors and is required for the assembly and formation of the germ plasm (Raz, 2000). Murine Mvh is expressed specifically in the germ cell lineages and is required for premeiotic differentiation in spermatocytes as well as development of male primordial germ cells (PGCs). While $\mathrm{Mvh}^{-/-}$spermatocytes arrest in the leptotene/zygotene stages, female germ cells are unaffected by the mutation (Tanaka et al. 2000).

Miwi and Mili are homologs of the Drosophila Piwi gene, which is involved in stem cell self-renewal, RNA silencing/processing, and translational regulation (Kuramochi-Miyagawa et al. 2001). In adults, Mili and Miwi are expressed specifically in the germ cells of the testis coinciding with the onset of spermatogenesis (KuramochiMiyagawa et al. 2001), while Mili is also expressed in female gonadal tissue from embryonic day 12.5 (e12.5) through birth (Kuramochi-Miyagawa et al. 2001). Mili ${ }^{-1-}$ mice have male-specific sterility due to spermatogenic arrest in late zygonema, while females are fertile (Kuramochi-Miyagawa et al. 2004). Miwi ${ }^{-/}$males are infertile due to disruption at the beginning of spermiogensis, while Miwi ${ }^{-/}$females are fully fertile (Deng \& Lin 2002). While their specific targets and mechanisms of actions are still unclear, Mvh, Mili, and Miwi all appear to be involved in post-transcriptional regulation during spermatogenesis via RNA processing.

\section{Cell cycle regulation}

The transition from prophase to $M$-phase of meiosis I is similar to the $\mathrm{G} 2-\mathrm{M}$ transition in the mitotic cell cycle, although adapting this transition for the meiotic cell cycle requires several significant modifications in cellular and molecular events. Separation of homologs, rather than sister chromatids, and timing considerations, such as dictyate arrest in oocytes, are just some of the additional problems facing meiotic cells at this transition, and the cellular machinery must adapt to regulate and monitor such events.

In both mitosis and meiosis, the transition into metaphase is regulated by activation of the maturation promoting factor (MPF), a complex composed of the CDC2 (CDK1) kinase and a B-type cyclin. In the stages leading up to this transition, cyclin B accumulates in the cell and CDC2 (CDK1) is activated by cyclin dependant kinase activation kinase (CAK) and by dephosphorylation via CDC25 phosphatase. The activation of CAK, associated with A-type cyclins, via slow A-type cyclin build up, results in the initiation of metaphase I. Although the role of CAK in meiosis has not been directly proven, its two 


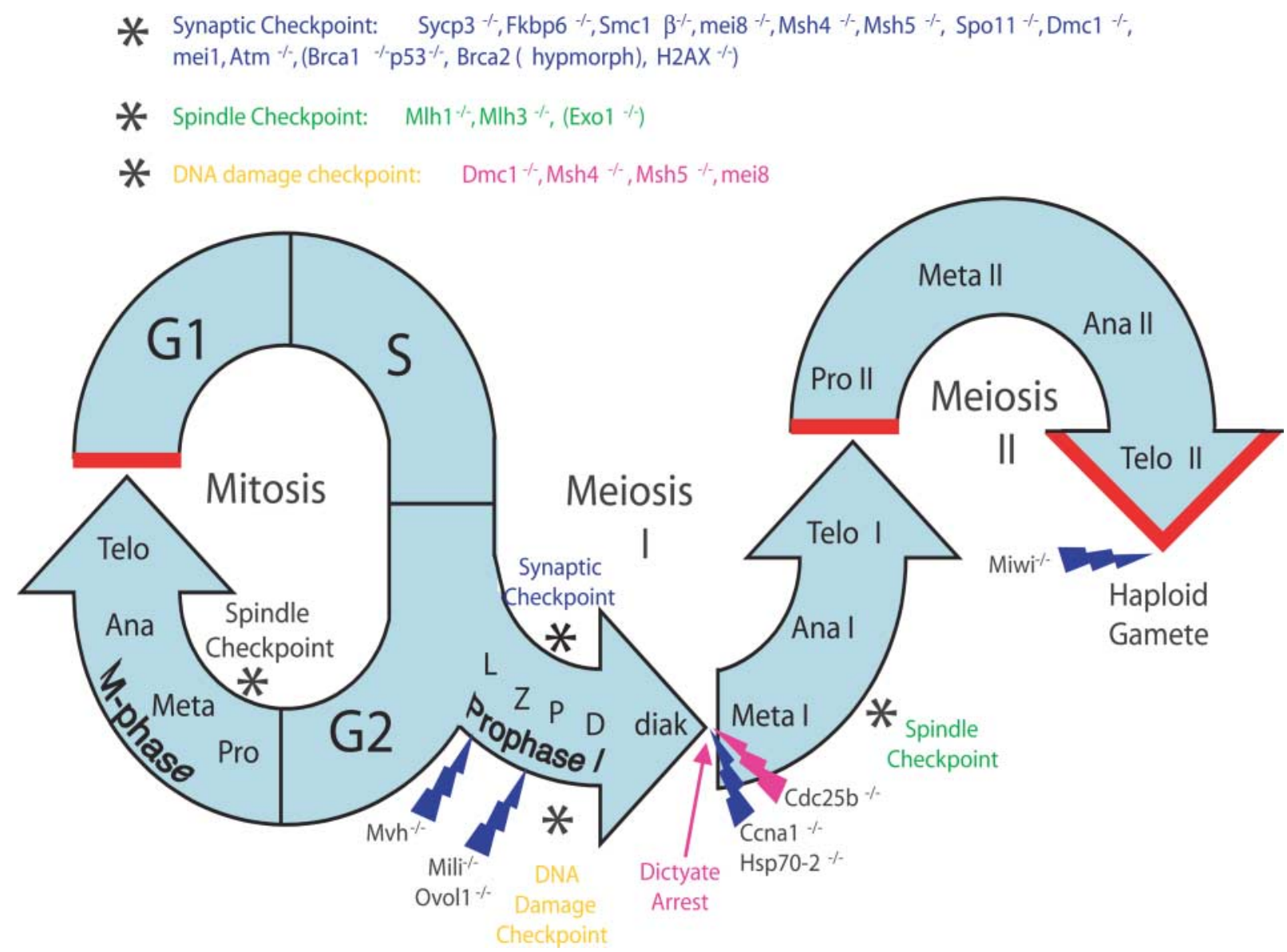

Figure 3 Cell cycle events in mouse gametogenesis. Checkpoints are indicated by asterisks. The stage at which meiosis is disrupted for a particular mutant mouse is indicated by a lightning bolt. Mouse mutants that succumb to these different checkpoints are listed at the top. Mutants listed in parentheses either exhibit only partial arrest at these checkpoints or it is currently unclear whether these mutants succumb to these checkpoints. Mutations that result in checkpoint activation only in males are depicted in blue, mutations that result in checkpoint activation only in females are depicted in pink, and mutations that are result in checkpoint activation in both sexes are depicted in green. The status of the yellow DNA damage checkpoint is unclear/unproven. Red lines indicate cell division points. Telo; Telophase, Ana; Anaphase, Meta; Metaphase, Pro; Prophase, L; leptonema, Z; zygonema, P; pachynema, D; diplonema, diaK; diakinesis.

core constituents, cyclin $\mathrm{H}$ and CDK7, are both expressed in spermatocytes from pachytene through diplotene. This suggests the existence of a meiotic role for these factors similar to their mitotic role. The meiotic cell cycle is reviewed in a number of excellent articles (Wolgemuth et al. 2002, Kishimoto 2003, Wolgemuth et al. 2004).

The cyclin dependent kinase, CDK2, is involved in both male and female meiosis, as indicated by the phenotype of male and female mice lacking a functional $C d k 2$ gene. In $\mathrm{Cdk} 2^{\%}$ males, spermatocytes progress through pachynema, but no diplotene cells are observed (Ortega et al. 2003). Even at earlier stages of prophase I, however, SYCP3 distribution is disrupted, with aggregates of SC proteins and discontinuous axes along the chromosomes. In addition, the presence of unpaired chromosomes suggests a role for CDK2 in pairing and synapsis. In Cdk2 ${ }^{--}$ females, oocytes progress apparently normally through pachynema and are lost soon after birth at a stage indicative of the onset of dictyate arrest (Ortega et al. 2003).
Another cyclin-dependent kinase, CKS2 (CDC28 protein kinase regulatory subunit 2), is essential for the transition into meiotic anaphase I, as indicated by the metaphase I arrest observed in male and female Cks2 null mice (Spruck et al. 2003). Other meiotic cell cycle regulators act specifically in male reproduction, as evidenced by reproductive phenotypes resulting from mutations in these genes (reviewed by Wolgemuth (2003)). These include, but are not limited to cyclin A1, p18 $8^{\text {INK } 4 C}$, and $p 19^{\text {INK4d }}$ (Zindy et al. 2001, Wolgemuth, 2003). A number of female cell cycle components appear to be involved in regulation of reproductive functions, but only CDC25b has been shown to be essential for female meiotic cell cycle regulation (Lincoln et al. 2002) (Fig. 3).

Cyclin A1 (encoded by Ccna1) is a germ cell specific cyclin thought to activate meiotic metaphase transition during meiosis I, in conjunction with MPF (Sweeney et al. 1996, Fuchimoto et al. 2001, Salazar et al. 2003, Wolgemuth et al. 2004). Ccna $1^{-1-}$ male mice are infertile due to 
spermatogenic arrest at the metaphase transition, likely to be due to impaired CDC2 (CDK1) kinase activation and spindle checkpoint activation (Liu et al. 1998, Liu et al. 2000). In somatic cells, the cyclin A1-CDK2 complex (in combination with the Ku70 DNA repair protein) has been shown to regulate DSB repair, at least in vitro (MullerTidow et al. 2004). Thus, it is possible that cyclin A1 serves a similar function in meiosis, presumably in the zygotene/pachytene transition, but this is confounded by the metaphase arrest seen in $\mathrm{Ccna}^{-/}$spermatocytes. Thus the role of cyclin A1 in male meiosis remains elusive. Although cyclin A2 is not generally highly expressed in meiosis (Fuchimoto et al. 2001), perhaps in females cyclin A2 is able to compensate for the lack of cyclin A1. However, examining the meiotic role of cyclin A2 is difficult as embryonic lethality of $\mathrm{CCna}^{-/-}$mice precludes genetic analysis (Murphy et al. 1999).

The need for specialized cell cycle regulatory events in females arises at the entry into dictyate arrest while spermatocytes procede straight through from diplonema to metaphase I. This is thought to be effected by femalespecific elevation of cyclic AMP, keeping protein kinase A (PKA), a cAMP dependent kinase, in its active state resulting in inhibitory phosphorylation of CDC25 and prevention of CDC2 (CDK1) activation and cell cycle progression (Kishimoto 2003). Oocyte release from dictyate arrest is thought to be similar to the mitotic transition into metaphase, involving MPF activation and alteration of CDC25 (the B form, see below) and myelin transcription factor (MYT1) levels (Kishimoto 2003). In Xenopus laevis, these events are triggered by hormonal signals, mostly increased progesterone levels, which activate protein kinase $B(P K B)$ via a G-protein pathway. This reverses the balance between the opposing forces of CDC25 and MYT1, allowing CDC25 activity to dominate, and resulting in CDC2 (CDK1) activation and cell cycle progression (Kishimoto 2003). Although evidence exists for the MAPK signaling pathway and other factors involvement in meiotic resumption, the collective result appears to be a shift in CDC25/MYT1 balance leading to MPF activation and ultimately release from dictyate arrest.

The Cdc25 genes encode a family of phosphatases involved in the activation of CDKs. They are key cell cycle regulators during the G1/S transition, S-phase, and entry into mitosis (via MPF activation), as well as mediating DNA damage checkpoint responses at the G2/M transition (Nilsson \& Hoffmann 2000, Perdiguero \& Nebreda 2004). Cdc25 overexpression is often correlated with cancer and tumorigenesis (Kristjansdottir \& Rudolph 2004). Cdc25a, Cdc25b and Cdc25c are members of this family, and perform various combinations of the general $C d c 25$ family functions mentioned above. Cdc25 genes also play a role meiotic cell cycle regulation (Lincoln et al. 2002, Perdiguero \& Nebreda 2004). All three Cdc25 family members have distinct, but overlapping roles in most cell populations, as evidenced by the absence or striking mildness of phenotypes if they are disrupted, even in double mutants, as well as their differential expression patterns (Wickramasinghe et al. 1995, Wu \& Wolgemuth 1995, Chen et al. 2001, Melkun et al. 2002, Ferguson et al. 2005). It is interesting to note, however, that Cdc25a and $C d c 25 c$ do not appear able to compensate for the absence of $C d c 25 b$ during meiotic resumption after dictyate arrest. $C d c 25 b$ is essential for the reactivation of MPF resulting in cell cycle resumption and exit from dictyate arrest and thus, $C d c 25 b^{-/-}$oocytes are not able to resume meiosis after dictyate arrest and females are rendered infertile (Lincoln et al. 2002) (Fig. 3). Despite being sterile, hormonal signaling and ovarian function appeared to be unaffected as folliculogenesis and ovulation occur normally in the absence of $C d c 25 b$, while male nulls display no spermatogenic abnormalities and are fertile (Lincoln et al. 2002).

Interestingly, CDC25B has recently been identified as a multi-steroid receptor cofactor including activity on the estrogen receptor (ER), potentiating histone acetyltransferase (HAT) activity and allowing transcription of downstream ER targets (Chua et al. 2004). Thus, CDC25B may act as a steroid receptor cofactor in the regulation of the hormone-dependent process of meiotic resumption after dictyate arrest, and this may explain the lack of phenotype in $C d c 25 b^{-/}$males as well as the inability of Cdc25a and $C d c 25 c$ to compensate for the absence of $C d c 25 b$ in oogenesis.

\section{Sex specific considerations of meiosis}

Certain characteristics of the male and female meiotic processes raise problems that one sex, but not the other, must cope with. For example, spermatocytes must find a way to address the inability of the $X$ and $Y$ chromosome to fully pair, and ensure their proper segregation in the absence of homology. Also, the testicular environment is kept $5-7^{\circ} \mathrm{C}$ cooler than the rest of the body, creating the need for a testis-specific response to temperature fluctuations. In females, an example of sex-specific consideration includes their need to initiate, maintain, and exit from dictyate arrest. In human females, extended periods of dictyate arrest give rise to a phenomenon called the maternal age effect. Such events are regulated by the coordinated effort of multiple pathways, including the cell cycle machinery, regulators of meiotic events, and cell extrinsic factors that regulate the hormonal milieu of the gonad, to name a few.

\section{Male-specific considerations}

Heat shock proteins (HSPs) may be involved in progression into meiotic metaphase I (Eddy, 1999) by acting as molecular chaperones to assist other proteins in folding, transport and assembly into complexes. The cooler temperature of the testicular environment relative to the rest of the body alludes to the possibility of a special role for HSPs and may also help explain the increased need for testis specific isoforms of proteins even when they perform 
identical functions. Hsp70-2 and Hsp70-T are spermatogenic specific HSPs. Hsp70-T is expressed in post-meiotic spermatids and Hsp70-2 is expressed abundantly from the beginning of meiosis to the post meiotic stages and is associated with the lateral elements from zygotene through diplotene (Allen et al. 1996). Hsp70-2-- male mice are sterile due to a metaphase transition failure associated with desynapsis and CDC2 kinase and MPF activation (Dix et al. 1996, 1997, Zhu et al. 1997, Eddy 1999). HSP70-2 may directly affect desynapsis via the mediation of SYCP1 dephosphorylation at the C-terminal CDC2 target site, or it may be involved in chaperoning and/or activating CDC2 (CDK1)/cyclin B complex. As such, these testis specific HSPs may participate in coordination of cell cycle and cytogenetic events in the face of the specialized temperature climate imposed by the testis. Whether this contributes to male-specific meiotic stringency remains to be determined.

In male mammals, the XY sex bivalent is the only chromosome pair that remains mostly unpaired through prophase I. Homologous interactions occur along a limited length of homology, the pseudoautosomal region (PAR), and it is at this site that the only recombination events occur between the pair. The XY bivalent possesses additional features that distinguish it from the autosomal bivalents: it is transcriptionally silenced from pachynema to metaphase in a process known as meiotic sex chromosome inactivation, $\mathrm{MSCl}$. During this time, the chromatin associated with the bivalent undergoes significant heterochromatinization to form the sex, or XY body (reviewed by Handel (2004)). The XY body forms a separate nuclear domain in which the unpaired region of the genome resides and it is characterized both by specific attachment to the nuclear lamina, and by the accumulation of unique $X Y$-associated proteins. The importance of the $X Y$ body is demonstrated by the observation that male mice, such $\mathrm{H} 2 \mathrm{ax}^{-/}$mice, that fail to produce an XY body in their pachytene spermatocytes, are sterile and exhibit meiotic disruption at pachynema (Celeste et al. 2002). Furthermore, the formation of this structure is specific to the cells in which they reside (spermatocytes), rather than a feature of either the $X$ or the $Y$ chromosome (Handel 2004).

The XY body also may play a role in the sexual dimorphism observed in X-autosome translocated mice. Male sterility occurs in all cases of $X$ autosomal translocations while females often are able to produce viable gametes despite being semi-sterile due to loss of unbalanced embryos (Ashley 2002). Since the XY body forms normally in these mice, it has been hypothesized that the increased vulnerability to infertility observed in male carriers of X-autosome translocations is due to intrusion of asynapsed autosomes into the sex body and/or transcriptional activation of X-linked genes normally inactivated during the transcriptional silencing of the XY body (Ashley 2002).

While a major function of the XY body is thought to be the separation of univalent chromosomes from the synaptic checkpoint machinery at pachynema, it is clear that events within this structure can initiate checkpoint events. In male mice with three sex chromosomes (XYY or XYY** some pachytene spermatocytes achieve full (trivalent) PAR synapsis, but in many cells one sex chromosome remains as a univalent (Hunt \& Eicher 1991). This triggers elimination via checkpoint activation, indicating that the checkpoint machinery does scan the XY body. However, sperm counts are significantly lower in male mice with four sex chromosomes $\left(X Y Y Y{ }^{*}\right.$ and $\left.X Y Y{ }^{*}{ }^{X}{ }^{*}{ }^{X}\right)$, despite complete PAR synapsis (either by the formation of radial quadrivalents or of two sex bivalents) (Rodriguez \& Burgoyne 2001), suggesting that checkpoint elimination has occurred despite appropriate synapsis. In this latter case, Rodriguez and Burgoyne have suggested that only a sex bivalent pair containing an $\mathrm{X}$ chromosome can undergo MCSI, since inactivation perhaps initiates on the $X$ chromosome through an Xist-independent mechanism (Turner et al. 2002), or that MCSI is sensitive to dosage. Either case would result in inappropriate $Y$ chromosome over-expression that could cause meiotic failure and/or checkpoint activation.

In summary, checkpoint mechanisms acting in male germ cells can respond to both sex chromosome asynapsis and to defects associated with MCSI, suggesting that the XY body plays an important role in monitoring appropriate meiotic progression. Whether such differences in dimorphism in the environmental status of the germ cells plays any role in the etiology of the sexually dimorphic stringency of meiotic progression through prophase I is unclear, but it is tantalizing to view such events as potential mediators of sex-specific monitoring at the chromosomal level.

\section{Female-specific considerations}

In addition to the altered prophase I machinery in females, oocytes have to contend with the detrimental effects of a lengthy dictyate arrest, often up to $40+$ years in women. The correlation between increased maternal age and an increase in the incidence of aneuploid conceptuses (Hassold \& Hunt 2001), the 'maternal age effect', suggests that prolonged dictyate arrest could result in additional oocyte damage, including spindle defects, breakdown in the sister chromatid cohesion over time, follicular development defects, or telomere abnormalities (Yin et al. 1998, Sun et al. 2001, Liu et al. 2002, Hunt et al. 2003, Liu et al. 2004, Pellestor, 2004, Prieto et al. 2004, Keefe et al. 2005) or, more likely, a combination thereof. By contrast, the second meiotic division which is not subject to the same lengthy time delay is consistently responsible for a considerably smaller fraction of aneuploidies compared to the those attributed to the first division (Hassold \& Hunt 2001). Similarly, both meiosis I and II in males occur without an intervening arrest period, such that spermatocytes are exposed to fewer potentially damaging events prior to fertilization.

Low crossover rates predispose oocytes to missegregation leading to aneuploidy, and oocytes from older 
women may be less able to overcome this susceptibility (Lamb \& Hassold 2004, Lamb et al. 1996). The increased recombination found in children born to older mothers supports the theory that aged oocytes need the additional security provided by a high number of recombination events to produce a viable pregnancy (Kong et al. 2004), suggesting that the increased chiasmata frequency in females may itself be an evolutionary mechanism designed to overcome the chiasma destabilization issues observed over time.

Although murine oocytes also exhibit dictyate arrest, they display only a moderate maternal age effect that is limited to certain mouse strains (Eichenlaub-Ritter et al. 1988). This may be due to the relatively short arrest time in murine oocytes (less than 2 years in mice compared to 10-40 years in women). Recently a maternal age effect- like phenomenon has been observed in the senescence accelerated mouse (SAM), a mouse model for aging, which displays metaphase defects similar to those observed in aged human oocytes (Liu \& Keefe 2002). The meiotic defects in SAM mice have been attributed to nuclear factors (Liu \& Keefe 2004), supporting the idea that DNA and/or chromosome damage, rather than extrinsic ageing factors, may be responsible for the reduced metaphase I progression. Such damage could be caused by routine ageing, or could be the result of environmental exposure to toxins and/or xenobiotic agents.

\section{Summary}

Meiosis has evolved significantly from the lower eukaryotes, such as yeast, which undergo meiosis as part of

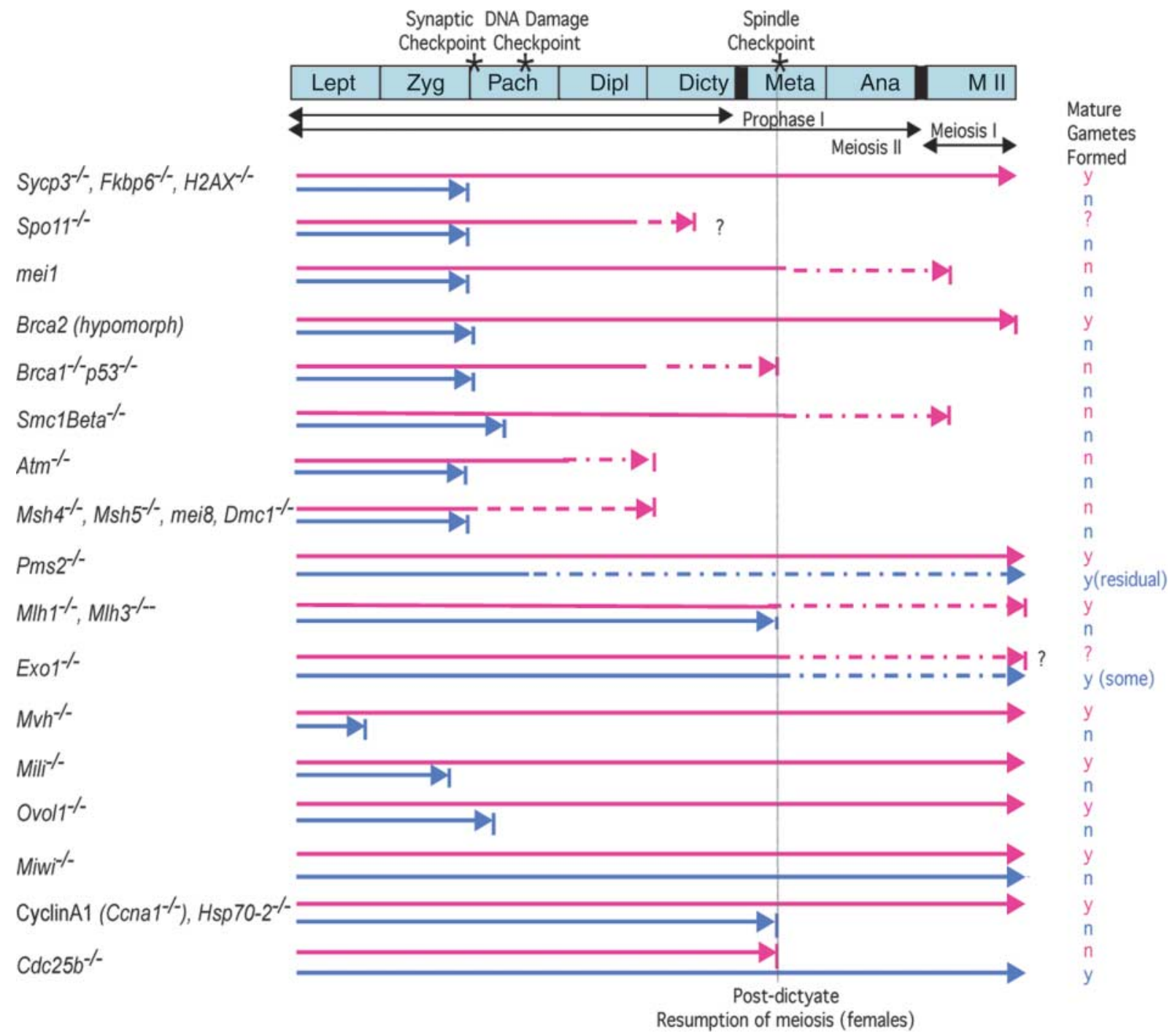

Figure 4 Meiotic progression in male and female mice exhibiting different mutant phenotypes. Blue indicates male meiotic progression, pink indicates female meiotic progression and solid arrows indicate seemingly normal meiotic progression. Dashed lines indicate that the cells persist but do not progress meiotically, whereas, the dashed and dotted lines indicate abnormal meiotic progression in a subset of the germ cell population, vertical line indicates failure to proceed beyond the stage indicated. Lept; leptonema, Zyg; zygonema, Pacn; pachynema, Dipl; diplonema, Dicty; dictyate, Meta: Metaphase, Ana; Anaphase. 
sporulation, to heterogametic higher eukaryotes, such as mammals, which have adapted their meiotic process to the needs of two distinct gametogenic processes. This is apparent from the numerous mutations that cause sexually dimorphic phenotypes in mice (summarized in Fig. 4). Examining the underlying causes of these phenotypes will help us understand the different biological problems posed by the female and male sexual environments, and may also help to explain elusive phenomena such as the high error rate in human female meiosis. These points underscore the need to study meiotic processes in both sexes in order to gain a more complete understanding of mammalian meiosis.

Clearly much has yet to be learned, not the least of which includes the relative importance of SC maintenance in male and female gametes, as well as the nature of the coupling between recombination events and cell cycle machinery. A greater understanding of how proteins such as ATM and BRCA1 signal to the cyclin-CDK complexes, perhaps through the check point kinases 1 and 2 (CHK1/CHK2) machinery, is a necessary next step towards the latter goal. Much of our knowledge of such processes has stemmed from an extensive body of research in somatic cell culture systems that, not surprisingly, may not translate readily into understanding meiotic processes. In somatic cells, for example, DSB events can be lethal or mutagenic, and are generally avoided. Meiotic cells, on the other hand, must purposefully induce such events and then repair them in a tightly controlled fashion, in an analogous fashion to that seen in somatic hypermutation. Additionally, meiocytes must take into account external influences such as hormonal environment, the well being of the individual and, in the case of females, conditions favoring intra-uterine growth and ovarian development.

This review has attempted to illustrate the extent of the sex-specific differences in male and female meiosis. However, more intriguing and elusive is the reason for the existence of these differences in the first place. One possibility is that the increased rate of miscarriage that results from aneuploid gametes is a mechanism for spacing concurrent successful pregnancies, providing a longer time to nurture each successive offspring, and allowing for the prolonged nurturing period exhibited by humans. As women age, this spacing effect would become more dramatic, perhaps allowing for more efficient use of the reduced resources available to older mothers. Our increased understanding of meiotic events across mammalian species and between the sexes will help to validate such theories.

\section{Acknowledgements}

Our thanks go to Drs Eric Alani, Laura Bannister, Wojtek Pawlowski, John Schimenti, and Claudia Sutton from Cornell University, Ithaca, NY, USA for reading this manuscript and for providing essential feedback. This work is supported by funding from the NICHD (1R01HD41012) and from the
March of Dimes (MOD1-FY2002-282) to P E Cohen. The authors declare that there is no conflict of interest that could prejudice the impartiality of this scientific work.

\section{References}

Allen JW, Dix DJ, Collins BW, Merrick BA, He C, Selkirk JK, Poorman-Allen P, Dresser ME \& Eddy EM 1996 HSP70-2 is part of the synaptonemal complex in mouse and hamster spermatocytes. Chromosoma 104 414-421.

Ashley T 2002 X-Autosome translocations, meiotic synapsis, chromosome evolution and speciation. Cytogenetic Genome Research 96 33-39.

Baarends WM \& Grootegoed A 2003 Chromatin dynamics in the male meiotic prophase. Cytogenetic Genome Research 103 225-234.

Baker SM, Bronner CE, Zhang L, Plug AK, Robatzek M, Warren G, Elliott EA, Yu J, Ashley T, Arnheim N et al. 1995 Male mice defective in the DNA mismatch repair gene PMS2 exhibit abnormal chromosome synapsis in meiosis. Cell 82 309-319.

Baker SM, Plug AW, Prolla TA, Bronner CE, Harris AC, Yao $X$, Christie DM, Monell C, Arnheim N \& Bradley A et al. 1996 Involvement of mouse Mlh1 in DNA mismatch repair and meiotic crossing over. Nature Genetics 13 336-342.

Bannister LA \& Schimenti JC 2004 Homologous recombinational repair proteins in mouse meiosis. Cytogenetic Genome Research 107 191-200.

Bannister LA, Reinholdt LG, Munroe RJ \& Schimenti JC 2004 Positional cloning and characterization of mouse mei8, a disrupted allele of the meiotic cohesin Rec8. Genesis 40 184-194.

Barlow AL \& Hulten MA 1996 Combined immunocytogenetic and molecular cytogenetic analysis of meiosis I human spermatocytes. Chromosome Research 4 562-573.

Barlow AL \& Hulten MA 1998a Combined immunocytogenetic and molecular cytogenetic analysis of meiosis I oocytes from normal human females. Zygote 6 27-38.

Barlow AL \& Hulten MA 1998 b Crossing over analysis at pachytene in man. European Journal of Human Genetics 6 350-358.

Barlow C, Hirotsune S, Paylor R, Liyanage M, Eckhaus M, Collins F, Shiloh Y, Crawley JN, Ried T \& Tagle D et al. 1996 Atm-deficient mice: a paradigm of ataxia telangiectasia. Cell 86 159-171.

Barlow C, Liyanage M, Moens PB, Tarsounas M, Nagashima K, Brown K, Rottinghaus S, Jackson SP, Tagle D, Ried T et al. 1998 Atm deficiency results in severe meiotic disruption as early as leptonema of prophase I. Development 125 4007-4017.

Baudat F, Manova K, Yuen JP, Jasin M \& Keeney S 2000 Chromosome synapsis defects and sexually dimorphic meiotic progression in mice lacking Spo11. Molecular Cell 6 989-998.

Boder E 1975 Ataxia-telangiectasia: some historic, clinical and pathologic observations. In Birth Defects Original Article Series, $11255-270$.

Brunet S, Pahlavan G, Taylor S \& Maro B 2003 Functionality of the spindle checkpoint during the first meiotic division of mammalian oocytes. Reproduction $126443-450$.

Celeste A, Petersen S, Romanienko PJ, Fernandez-Capetillo $O$, Chen HT, Sedelnikova OA, Reina-San-Martin B, Coppola V, Meffre E, Difilippantonio MJ et al. 2002 Genomic instability in mice lacking histone H2AX. Science $296922-927$.

Chen J \& Sadowski I 2005 Identification of the mismatch repair genes PMS2 and MLH1 as p53 target genes by using serial analysis of binding elements. PNAS 102 4813-4818.

Chen M, Hurov J, White L, Woodford-Thomas T \& Piwnica-Worms H 2001 Absence of apparent phenotype in mice lacking Cdc25C protein phosphatase. Molecular and Cellular Biology 21 3853-3861.

Chua SS, Ma Z, Ngan E \& Tsai S 2004 CDC25B as a Steroid Receptor Coactivator. Vitamins and Hormones $68231-256$. 
Crackower MA, Kolas NK, Noguchi J, Sarao R, Kikuchi K, Kaneko H, Kobayashi E, Kawai Y, Kozieradzki I, Landers R et al. 2003 Essential role of Fkbp6 in male fertility and homologous chromosome pairing in meiosis. Science $\mathbf{3 0 0}$ 1291-1295.

Cressman VL, Backlund DC, Avrutskaya AV, Leadon SA, Godfrey V \& Koller BH 1999 Growth retardation, DNA repair defects, and lack of spermatogenesis in BRCA1 deficient mice. Molecular and Cellular Biology $197061-7075$.

Dai X, Schonbaum C, Degenstein L, Bai W, Mahowald A \& Fuchs E 1998 The ovo gene required for cuticle formation and oogenesis in flies is involved in hair formation and spermatogenesis in mice. Genes \& Development 12 3452-3463.

Deng W \& Lin H 2002 Miwi, a murine homolog of piwi, encodes a cytoplasmic protein essential for spermatogenesis. Developmental Cell 2 819-830.

Di Giacomo M, Barchi M, Baudat F, Edelmann W, Keeney S \& Jasin M 2005 Distinct DNA-damage-dependent and -independent responses drive the loss of oocytes in recombination-defective mouse mutants. PNAS 102 737-742.

Dix DJ, Allen JW, Collins BW, Mori C, Nakamura N, Poorman-Allen P, Goulding EH \& Eddy EM 1996 Targeted gene disruption of Hsp70-2 results in failed meiosis, germ cell apoptosis, and male infertility. PNAS 93 3264-3268.

Dix DJ, Allen JW, Collins BW, Poorman-Allen P, Mori C, Blizard DR, Brown PR, Goulding EH, Strong BD \& Eddy EM 1997 HSP70-2 is required for desynapsis of synaptonemal complexes during meiotic prophase in juvenile and adult mouse spermatocytes. Development 124 4595-4603.

Eaker S, Pyle A, Cobb J \& Handel MA 2001 Evidence for melotic spindle checkpoint from analysis of spermatocytes from Robertsonian-chromosome heterozygous mice. Journal of Cell Science $\mathbf{1 1 4}$ 2953-2965.

Eaker S, Cobb J, Pyle A \& Handel MA 2002 Meiotic prophase abnormalities and metaphase cell death in MLH1-deficient mouse spermatocytes: insights into regulation of spermatogenic progress. Developmental Biology 249 85-95.

Easton DF, Ford D \& Bishop DT 1995 Breast and ovarian cancer incidence in BRCA1 mutation carriers. Breast Cancer Linkage Consortium. American Journal of Human Genetics 56 265-271.

Eddy EM 1999 Role of heat shock protein HSP70-2 in spermatogenesis. Reviews of Reproduction 4 23-30.

Edelmann W, Cohen PE, Kane M, Lau K, Morrow B, Bennett S, Umar A, Kunkel T, Cattoretti G, Chaganti R et al. 1996 Meiotic pachytene arrest in MLH1-deficient mice. Cell 85 1125-1134.

Edelmann W, Cohen PE, Kneitz B, Winand N, Lia M, Heyer J, Kolodner R, Pollard JW \& Kucherlapati R 1999 Mammalian MutS homologue 5 is required for chromosome pairing in meiosis. Nature Genetics 21 123-127.

Eichenlaub-Ritter U, Chandley AC \& Gosden RG 1988 The CBA mouse as a model for age-related aneuploidy in man: studies of oocyte maturation, spindle formation and chromosome alignment during meiosis. Chromosoma 96 220-226.

Evans CW, Robb DI, Tuckett F \& Chanlloner S 1982 Regulation of meiosis in the foetal mouse gonad. Journal of Embryology and Experimental Morphology 68 59-67.

Ferguson A, White L, Donovan P \& Piwnica-Worms H 2005 Normal cell cycle and checkpoint responses in mice and cells lacking Cdc25B and Cdc25C protein phosphatases. Molecular and Cellular Biology $252853-2860$.

Fuchimoto D-I, Mizukoshi A, Schultz RM, Sakai S \& Aoki F 2001 Posttranscriptional Regulation of Cyclin A1 and Cyclin A2 During Mouse Oocyte Meiotic Maturation and Preimplantation Development. Biology of Reproduction 65 986-993.

Fujiwara Y, Komiya T, Kawabata H, Sato M, Fujimoto H, Furusawa M \& Noce T 1994 Isolation of a DEAD-family protein gene that encodes a murine homolog of Drosophila vasa and its specific expression in germ cell lineage. PNAS 91 12258-12262.

Handel M 2004 The XY body: a specialized meiotic chromatin domain. Experimental Cell Research 296 57-63.
Handel MA \& Eppig JJ 1998 Sexual dimorphism in the regulation of mammalian meiosis. Current Topics in Developmental Biology 37 $333-358$

Hassold T \& Hunt P 2001 To err (meiotically) is human: the genesis of human aneuploidy. Nature Reviews Genetics 2 280-291.

Hassold T, Sherman S \& Hunt P 2000 Counting cross-overs: characterizing meiotic recombination in mammals. Human Molecular Genetics 9 2409-2419.

Hawley RS 2002 Meiosis: how male flies do meiosis. Current Biology 12 R660-R662.

Hodges CA, LeMaire-Adkins R \& Hunt PA 2001 Coordinating the segregation of sister chromatids during the first meiotic division: evidence for sexual dimorphism. Journal of Cell Science 114 2417-2426.

Homer H, McDougall A, Levasseur M \& Herbert M 2005a Restaging the Spindle Assembly Checkpoint in Female Mammalian Meiosis I. Cell Cycle 4.

Homer HA, McDougall A, Levasseur M \& Herbert M 2005b RNA interference in meiosis I human oocytes: towards an understanding of human aneuploidy. Molecular Human Reproduction (in press).

Homer HA, McDougall A, Levasseur M, Yallop K, Murdoch AP \& Herbert M 2005C Mad2 prevents aneuploidy and premature proteolysis of cyclin B and securin during meiosis I in mouse oocytes. Genes \& Development 19 202-207.

Hopper JL, Southey MC, Dite GS, Jolley DJ, Giles GG, McCredie MR, Easton DF \& Venter DJ 1999 Population-based estimate of the average age-specific cumulative risk of breast cancer for a defined set of protein-truncating mutations in BRCA1 and BRCA2. Australian Breast Cancer Family Study. Cancer Epidemiology Biomarkers and Prevention 8 741-747.

Hunt PA \& Eicher EM 1991 Fertile male mice with three sex chromosomes: evidence that infertility in XYY male mice is an effect of two Y chromosomes. Chromosoma 100 293-299.

Hunt PA, Koehler KE, Susiarjo M, Hodges CA, Ilagan A, Voigt RC, Thomas S, Thomas BF \& Hassold TJ 2003 Bisphenol a exposure causes meiotic aneuploidy in the female mouse. Current Biology 13 546-553.

Jessberger R 2002 The many functions of SMC proteins in chromosome dynamics. Nature Reviews Molecular and Cellular Biology 3 $767-778$.

Keefe D, Franco S, Liu L, Trimarchi J, Cao B, Weitzen S, Agarwal S \& Blasco M 2005 Telomere length predicts embryo fragmentation after in vitro fertilization in women - toward a telomere theory of reproductive aging in women. American Journal of Obstetrics and Gynecology 192 1256-1261.

Keeney S, Giroux CN \& Kleckner N 1997 Meiosis-specific DNA double-strand breaks are catalyzed by Spo11, a member of a widely conserved protein family. Cell 88 375-384.

Kishimoto T 2003 Cell-cycle control during meiotic maturation. Current Opinion in Cell Biology 15 654-663.

Klein U, Esposito G, Baudat F, Keeney S \& Jasin M 2002 Mice deficient for the type II topoisomerase-like DNA transesterase Spo11 show normal immunoglobulin somatic hypermutation and class switching. European Journal of Immunology 32 316-321.

Kneitz B, Cohen PE, Avdievich E, Zhu L, Kane MF, Hou H Jr, Kolodner RD, Kucherlapati R, Pollard JW \& Edelmann W 2000 MutS homolog 4 localization to meiotic chromosomes is required for chromosome pairing during meiosis in male and female mice. Genes \& Development 14 1085-1097.

Kolas NK \& Cohen PE 2004 Novel and diverse functions of the DNA mismatch repair family in mammalian meiosis and recombination. Cytogenetic Genome Research 107 216-231.

Kolas NK, Yuan L, Hoog C, Heng HH, Marcon E \& Moens PB 2004 Male mouse meiotic chromosome cores deficient in structural proteins SYCP3 and SYCP2 align by homology but fail to synapse 
and have possible impaired specificity of chromatin loop attachment. Cytogenetic Genome Research 105 182-188.

Kolas N, Marcon E, Spyropoulos B \& Moens PB 2005 Mutant meiotic chromosome core components in mice can cause an apparent sexual dimorphic endpoint at prophase or $\mathrm{X}-\mathrm{Y}$ defective male specific sterility. Chromosoma 114 92-102.

Kong A, Barnard J, Gudbjartsson D, Thorleifsson G, Jonsdottir G, Sigurdardottir S, Richardsson B, Jonsdottir J, Thorgeirsson T \& Frigge $\mathbf{M}$ et al. 2004 Recombination rate and reproductive success in humans. Nature Genetics 36 1203-1206.

Kouznetsova A, Novak I, Jessberger R \& Hoog C 2005 SYCP2 and SYCP3 are required for cohesin core integrity at diplotene but not for centromere cohesion at the first meiotic division. Journal of Cell Science 118 2271-2278.

Kristjansdottir K \& Rudolph J 2004 Cdc25 phosphatases and cancer. Chemistry \& Biology 11 1043-1051.

Kuramochi-Miyagawa S, Kimura T, Yomogida K, Kuroiwa A, Tadokoro Y, Fujita Y, Sato M, Matsuda Y \& Nakano T 2001 Two mouse piwi-related genes: miwi and mili. Mechinisms of Development $108121-133$.

Kuramochi-Miyagawa S, Kimura T, Ijiri T, Isobe T, Asada N, Fujita $\mathrm{Y}$, Ikawa M, Iwai N, Okabe M, Deng W et al. 2004 Mili, a mammalian member of piwi family gene, is essential for spermatogenesis. Development 131 139-149.

Lamb NE \& Hassold TJ 2004 Nondisjunction-a view from ringside. New England Journal of Medicine 351 1931-1934.

Lamb NE, Freeman SB, Savage-Austin A, Pettay D, Taft L, Hersey J, Gu Y, Shen J, Saker D, May KM et al. 1996 Susceptible chiasmate configurations of chromosome 21 predispose to non-disjunction in both maternal meiosis I and meiosis II. Nature Genetics 14 400-405.

Lavin M, Birrell G, Chen P, Kozlov S, Scott S \& Gueven N 2005 ATM signaling and genomic stability in response to DNA damage. Mutation Research 569 123-132.

Lenzi ML, Smith J, Snowden T, Kim M, Fishel R, Poulos BK \& Cohen PE 2004 Extreme Heterogeneity in the Molecular Events Leading to the Establishment of Chiasmata during Meiosis I in Human Oocytes. American Journal of Human Genetics $\mathbf{7 6}$.

Lenzi ML, Smith J, Snowden T, Kim M, Fishel R, Poulos BK \& Cohen PE 2005 Extreme heterogeneity in the molecular events leading to the establishment of chiasmata during meiosis $i$ in human oocytes. American Journal of Human Genetics 76 112-127.

Li B, Nair M, Mackay D, Bilanchone V, Hu M, Fallahi M, Song H, Dai Q, Cohen P \& Dai X 2005 Ovol1 regulates meiotic pachytene progression during spermatogenesis by repressing Id2 expression. Development 132 1463-1473.

Libby BJ, De La Fuente R, O'Brien MJ, Wigglesworth K, Cobb J, Inselman A, Eaker S, Handel MA, Eppig JJ \& Schimenti JC 2002 The mouse meiotic mutation mei1 disrupts chromosome synapsis with sexually dimorphic consequences for meiotic progression. Developmental Biology 242 174-187.

Libby BJ, Reinholdt LG \& Schimenti JC 2003 Positional cloning and characterization of Mei1, a vertebrate-specific gene required for normal meiotic chromosome synapsis in mice. PNAS $\mathbf{1 0 0}$ 15706-15711.

Liebe B, Alsheimer M, Hoog C, Benavente R \& Scherthan H 2004 Telomere attachment, meiotic chromosome condensation, pairing, and bouquet stage duration are modified in spermatocytes lacking axial elements. Molecular Biology of the Cell 15 827-837.

Lincoln AJ, Wickramasinghe D, Stein P, Schultz RM, Palko ME, De Miguel MP, Tessarollo L \& Donovan PJ 2002 Cdc25b phosphatase is required for resumption of meiosis during oocyte maturation. Nature Genetics 30 446-449.

Lipkin SM, Moens PB, Wang V, Lenzi M, Shanmugarajah D, Gilgeous A, Thomas J, Cheng J, Touchman JW, Green ED et al. 2002 Meiotic arrest and aneuploidy in MLH3 deficient mice. Nature Genetics 31 385-390.

Liu D, Matzuk MM, Sung WK, Guo Q, Wang P \& Wolgemuth DJ 1998 Cyclin A1 is required for meiosis in the male mouse. Nature Genetics $20377-380$.
Liu D, Liao C \& Wolgemuth DJ 2000 A role for cyclin A1 in the activation of MPF and G2-M transition during meiosis of male germ cells in mice. Developmental Biology 224 388-400.

Liu L \& Keefe DL 2002 Ageing-associated aberration in meiosis of oocytes from senescence-accelerated mice. Human Reproduction 17 2678-2685.

Liu L \& Keefe DL 2004 Nuclear origin of aging-associated meiotic defects in senescence-accelerated mice. Biology of Reproduction 71 1724-1729.

Liu L, Blasco MA \& Keefe DL 2002 Requirement of functional telomeres for metaphase chromosome alignments and integrity of meiotic spindles. EMBO Reports 3 230-234.

Liu L, Franco S, Spyropoulos B, Moens PB, Blasco MA \& Keefe DL 2004 Irregular telomeres impair meiotic synapsis and recombination in mice. PNAS 101 6496-6501.

Lynn A, Koehler KE, Judis L, Chan ER, Cherry JP, Schwartz S, Seftel A, Hunt PA \& Hassold TJ 2002 Covariation of synaptonemal complex length and mammalian meiotic exchange rates. Science 296 2222-2225.

Lynn A, Ashley T \& Hassold T 2004 Variation in human meiotic recombination. Annual Reviews of Genomics and Human Genetics 5 317-349.

Masson JY \& West SC 2001 The Rad51 and Dmc1 recombinases: a non-identical twin relationship. Trends in Biochemical Sciences $\mathbf{2 6}$ 131-136.

McKee BD 1998 Pairing sites and the role of chromosome pairing in meiosis and spermatogenesis in male Drosophila. Current Topics in Developmental Biology 37 77-115.

McKee BD 2004 Homologous pairing and chromsome dynamics in meiosis and mitosis. Biochimica et Biophysica Acta 1677 165-180.

Melkun E, Pilione M \& Paulson R 2002 A naturally occurring point substitution in Cdc25A, and not Fv2/Stk, is associated with altered cell-cycle status of early erythroid progenitor cells. Blood $\mathbf{1 0 0}$ 3804-3811.

Moens PB \& Spyropoulos B 1995 Immunocytology of chiasmata and chromosomal disjunction at mouse meiosis. Chromosoma 104 $175-182$.

Moens PB, Kolas NK, Tarsounas M, Marcon E, Cohen PE \& Spyropoulos B 2002 The time course and chromosomal localization of recombination-related proteins at meiosis in the mouse are compatible with models that can resolve the early DNA-DNA interactions without reciprocal recombination. Journal of Cell Science 115 1611-1622.

Muller-Tidow C, Ji P, Diederichs S, Potratz J, Baumer N, Kohler G, Cauvet T, Choudary C, van der Meer T, Chan W et al. 2004 The cyclin A1-CDK2 complex regulates DNA double-strand break repair. Molecular and Cellular Biology 24 8917-8928.

Murphy $M$, Stinnakre $M$, Senamaud-Beaufort $C$, Winston N, Sweeney $C$, Kubelka M, Carrington $M$, Brechot $C$ \& Sobczak-Thepot J 1999 Delayed early embryonic lethality following disruption of the murine cyclin A2 gene. Nature Genetics 23481.

Nilsson I \& I 2000 Cell cycle regulation by the Cdc25 phosphatase family. Progress in Cell Cycle Research 4 107-114.

Ortega S, Prieto I, Odajima J, Martin A, Dubus P, Sotillo R, Barbero JL, Malumbres M \& Barbacid M 2003 Cyclin-dependent kinase 2 is essential for meiosis but not for mitotic cell division in mice. Nature Genetics 35 25-31.

Page SL \& Hawley RS 2004 The genetics and molecular biology of the synaptonemal complex. Annual Reviews in Cell Developmental Biology 20 525-558.

Pellestor F 2004 Maternal age and chromosomal abnormalities in human oocytes. Medical Science 20 691-696.

Perdiguero E \& Nebreda AR 2004 Regulation of Cdc25C Activity During the Meiotic G(2)/M Transition. Cell Cycle 3 733-737.

Pittman DL, Cobb J, Schimenti KJ, Wilson LA, Cooper DM, Brignull E, Handel MA \& Schimenti JC 1998 Meiotic prophase arrest with failure of chromosome synapsis in mice deficient for Dmc1, a germline-specific RecA homolog. Molecular Cell $\mathbf{1}$ 697-705. 
Plug AW, Peters AH, Xu Y, Keegan KS, Hoekstra MF, Baltimore D, de Boer P \& Ashley T 1997 ATM and RPA in meiotic chromosome synapsis and recombination. Nature Genetics 17 457-461.

Plug AW, Peters AH, Keegan KS, Hoekstra MF, de Boer P \& Ashley T 1998 Changes in protein composition of meiotic nodules during mammalian meiosis. Journal of Cell Science 111 413-423.

Prieto I, Tease C, Pezzi N, Buesa JM, Ortega S, Kremer L, Martinez A, Martinez AC, Hulten MA \& Barbero JL 2004 Cohesin component dynamics during meiotic prophase I in mammalian oocytes. Chromosome Research 12 197-213.

Pyle A \& Handel MA 2003 Meiosis in male PL/J mice: A genetic model for gametic aneuploidy. Molecular Reproduction and Development 64 471-481.

Radanyi C, Chambraud B \& Baulieu EE 1994 The ability of the immunophilin FKBP59HBI to interact with the 90-kDa heat shock protein is encoded by its tetratricopeptide repeat domain. PNAS 91 11197-11201.

Raz E 2000 The function and regulation of vasa-like genes in germcell development. Genome Biology 1 Reviews 1017.

Reddy RK, Kurek I, Silverstein AM, Chinkers M, Breiman A \& Krishna P 1998 High- molecular-weight FK506-binding proteins are components of heat-shock protein 90 heterocomplexes in wheat germ lysate. Plant Physiology 118 1395-1401.

Revenkova E \& Jessbergen R 2005 Keeping sister chromatids together: cohesins in meiosis. Reproduction 130 783-790.

Revenkova E, Eijpe M, Heyting C, Hodges CA, Hunt PA, Liebe B, Scherthan H \& Jessberger R 2004 Cohesin SMC1beta is required for meiotic chromosome dynamics, sister chromatid cohesion and DNA recombination. Nature Cell Biology 6 555-562.

Richardson C, Horikoshi N \& Pandita TK 2004 The role of DNA double-stranded break response network in meiosis. DNA Repair 3 1149-1164.

Rodriguez T \& Burgoyne P 2001 Spermatogenic failure in male mice with four sex chromosomes. Chromosoma 110 124-129.

Roig I, Liebe B, Egozcue J, Cabero L, Garcia M \& Scherthan H 2004 Female-specific features of recombinational double-stranded DNA repair in relation to synapsis and telomere dynamics in human oocytes. Chromosoma 113 22-33.

Romanienko PJ \& Camerini-Otero RD 2000 The mouse Spo11 gene is required for meiotic chromosome synapsis. Molecular Cell 6 975-987.

Salazar G, Liu D, Liao C, Batkiewicz L, Arbing R, Chung SS, Lele K \& Wolgemuth DJ 2003 Apoptosis in male germ cells in response to cyclin A1-deficiency and cell cycle arrest. Biochemical Pharmacology 66 1571-1579.

Sharan SK, Pyle A, Coppola V, Babus J, Swaminathan S, Benedict J, Swing D, Martin BK, Tessarollo L, Evans JP et al. 2004 BRCA2 deficiency in mice leads to meiotic impairment and infertility. Development 131 131-142.

Shinohara A, Gasior S, Ogawa T, Kleckner N \& Bishop DK 1997 Saccharomyces cerevisiae recA homologues RAD51 and DMC1 have both distinct and overlapping roles in meiotic recombination. Genes Cells 2 615-629.

Spruck CH, de Miguel MP, Smith AP, Ryan A, Stein P, Schultz RM, Lincoln AJ, Donovan PJ \& Reed SI 2003 Requirement of Cks2 for the first metaphase/anaphase transition of mammalian meiosis. Science 300 647-650.

Sun F, Yin H \& Eichenlaub-Ritter U 2001 Differential chromosome behaviour in mammalian oocytes exposed to the tranquilizer diazepam in vitro. Mutagenesis 16 407-417.

Svetlanov A \& Cohen PE 2004 Mismatch repair proteins, meiosis, and mice: understanding the complexities of mammalian meiosis. Experimental Cell Research 296 71-79.

Sweeney C, Murphy M, Kubelka M, Ravnik SE, Hawkins CF, Wolgemuth DJ \& Carrington M 1996 A distinct cyclin A is expressed in germ cells in the mouse. Development 122 53-64.
Tai P, Albers M, Chang H, Faber L \& Schreiber S 1992 Association of a 59kilodalton immunophilin with the glucocorticoid receptor complex. Science 256 1215-1218.

Tanaka SS, Toyooka Y, Akasu R, Katoh-Fukui Y, Nakahara Y, Suzuki R, Yokoyama M \& Noce T 2000 The mouse homolog of Drosophila Vasa is required for the development of male germ cells. Genes \& Development 14 841-853.

Taylor S, Scott M \& Holland A 2004 The spindle checkpoint: a quality control mechanism which ensures accurate chromosome segregation. Chromosome Research 12 599-616.

Tease C \& Hulten M 2004 Inter-sex variation in synaptonemal complex lengths largely determine the different recombination rates in male and female germ cells. Cytogenetics and Genome Research 107 208-215.

Tease C, Hartshorne GM \& Hulten MA 2002 Patterns of meiotic recombination in human fetal oocytes. American Journal of Human Genetics 70 1469-1479.

Turner JM, Mahadevaiah SK, Elliott DJ, Garchon HJ, Pehrson JR, Jaenisch R \& Burgoyne PS 2002 Meiotic sex chromosome inactivation in male mice with targeted disruptions of Xist. Journal of Cell Science 115 4097-4105.

Turner JM, Aprelikova O, Xu X, Wang R, Kim S, Chandramouli GV, Barrett JC, Burgoyne PS \& Deng CX 2004 BRCA1 histone H2AX phosphorylation, and male meiotic sex chromosome inactivation. Current Biology 14 2135-2142.

Turner J, Mahadevaiah S, Fernandez-Capetillo $O$, Nussenzweig A, Xu X, Deng C \& Burgoyne P 2005 Silencing of unsynapsed meiotic chromosomes in the mouse. Nature Genetics 37 41-47.

Vazquez J, Belmont AS \& Sedat JW 2002 The dynamics of homologous chromosome pairing during male Drosophila meiosis. Current Biology 12 1473-1483.

Wang TF, Kleckner N \& Hunter N 1999 Functional specificity of MutL homologs in yeast: evidence for three Mlh1-based heterocomplexes with distinct roles during meiosis in recombination and mismatch correction [see comments]. PNAS 96 13914-13919.

Wei K, Clark AB, Wong E, Kane MF, Mazur DJ, Parris T, Kolas NK, Russell R, Hou H Jr \& Kneitz B et al. 2003 Inactivation of Exonuclease 1 in mice results in DNA mismatch repair defects, increased cancer susceptibility, and male and female sterility. Genes \& Development 17 603-614.

Wickramasinghe D, Becker S, Ernst M, Resnick J, Centanni J, Tessarollo L, Grabel L \& Donovan P 1995 Two CDC25 homologues are differentially expressed during mouse development. Development $1212047-2056$

Wolgemuth DJ 2003 Insights into regulation of the mammalian cell cycle from studies on spermatogenesis using genetic approaches in animal models. Cytogenetic Genome Research 103 256-266.

Wolgemuth DJ, Laurion E \& Lele KM 2002 Regulation of the mitotic and meiotic cell cycles in the male germ line. Recent Progress in Hormone Research 57 75-101.

Wolgemuth DJ, Lele KM, Jobanputra V \& Salazar G 2004 The A-type cyclins and the meiotic cell cycle in mammalian male germ cells. International Journal of Andrology 27 192-199.

Woods LM, Hodges CA, Baart E, Baker SM, Liskay M \& Hunt PA 1999 Chromosomal influence on meiotic spindle assembly: abnormal meiosis I in female Mlh1 mutant mice. Journal of Cell Biology 145 1395-1406.

Wooster R, Bignell G, Lancaster J, Swift S, Seal S, Mangion J, Collins N, Gregory S, Gumbs C \& Micklem G 1995 Identification of the breast cancer susceptibility gene BRCA2. Nature 378 789-792.

Wu S \& Wolgemuth D 1995 The distinct and developmentally regulated patterns of expression of members of the mouse Cdc25 gene family suggest differential functions during gametogenesis. Developmental Biology. 170 195-206.

Xu Y, Ashley T, Brainerd EE, Bronson RT, Meyn MS \& Baltimore D 1996 Targeted disruption of ATM leads to growth retardation, 
chromosomal fragmentation during meiosis, immune defects, and thymic lymphoma. Genes \& Development 10 2411-2422.

Xu X, Aprelikova O, Moens P, Deng CX \& Furth PA 2003 Impaired meiotic DNA-damage repair and lack of crossing-over during spermatogenesis in BRCA1 full-length isoform deficient mice. Development $1302001-2012$.

Yin H, Cukurcam S, Betzendahl I, Adler ID \& Eichenlaub-Ritter U 1998 Trichlorfon exposure, spindle aberrations and nondisjunction in mammalian oocytes. Chromosoma 107 514-522.

Yoshida K, Kondoh G, Matsuda Y, Habu T, Nishimune Y \& Morita T 1998 The mouse RecA-like gene Dmc1 is required for homologous chromosome synapsis during meiosis. Molecular Cell 1 707-718.

Yuan L, Liu JG, Zhao J, Brundell E, Daneholt B \& Hoog C 2000 The murine SCP3 gene is required for synaptonemal complex assembly, chromosome synapsis, and male fertility. Molecular Cell $573-83$.

Yuan L, Liu JG, Hoja MR, Wilbertz J, Nordqvist K \& Hoog C 2002 Female germ cell aneuploidy and embryo death in mice lacking the meiosis-specific protein SCP3. Science 296 1115-1118.
Zhu D, Dix DJ \& Eddy EM 1997 HSP70-2 is required for CDC2 kinase activity in meiosis I of mouse spermatocytes. Development 124 3007-3014.

Zickler D \& Kleckner N 1999 Meiotic chromosomes: integrating structure and function. Annual Reviews of Genetics 33 $603-754$.

Zindy F, den Besten W, Chen B, Rehg JE, Latres E, Barbacid M, Pollard JW, Sherr CJ, Cohen PE \& Roussel MF 2001 Control of spermatogenesis in mice by the cyclin D-dependent kinase inhibitors p18(Ink4c) and p19(Ink4d). Molecular and Cellular Biology 21 $3244-3255$.

Received 4 July 2005

First decision 6 July 2005

Revised manuscript received 11 July 2005

Accepted 22 August 2005 